Rev. Inst. Flor. v. 29 n. 1 p. $91-119$ jun. 2017

http://dx.doi.org/10.24278/2178-5031.201729106

ISSN impresso 0103-2674/on-line 2178-5031

\title{
REGENERAÇÃO NATURAL DA FLORESTA OMBRÓFILA DENSA APÓS OITO ANOS DE ABANDONO DE ATIVIDADES AGRÍCOLAS EM MIRACATU, VALE DO RIBEIRA, SP ${ }^{1}$
}

\author{
NATURAL REGENERATION OF THE OMBROPHYLOUS DENSE FOREST \\ AFTER EIGHT YEARS OF ABANDONMENT OF AGRICULTURAL ACTIVITIES \\ IN MIRACATU, RIBEIRA VALLEY, SP
}

Claudio de MOURA ${ }^{2,4}$; Waldir MANTOVANI ${ }^{3}$

\begin{abstract}
RESUMO - Este trabalho descreveu o processo de sucessão da vegetação em regeneração natural de uma área de floresta suprimida para introdução da bananicultura na Estação Ecológica Juréia-Itatins após oito anos de abandono das atividades agrícolas. Foram efetuados os levantamentos florísticos e fitossociológicos em cinco parcelas de $10 \times 25 \mathrm{~m}$, onde todos os indivíduos de porte arbustivo-arbóreo $\geq 1 \mathrm{~m}$ de altura foram coletados e registrados a altura e perímetro das plantas e as espécies foram classificadas em síndromes de dispersão e grupos sucessionais. A estrutura da floresta foi analisada por meio dos parâmetros fitossociológicos usuais, índice de diversidade de Shannon ( $\left.\mathrm{H}^{\prime}\right)$ e equabilidade (J'). Foram amostrados 1.440 indivíduos de 149 espécies e 59 famílias, sendo Melastomataceae (29), Myrtaceae (15), Fabaceae (10) e Rubiaceae (9) as famílias de maior riqueza, predominando espécies pioneiras e secundárias iniciais $(36,91 \%)$ e zoocóricas $(54,36 \%)$. As espécies com os maiores valores de cobertura foram Tibouchina pulchra, Leandra variabilis, Miconia cinnamomifolia e Piptocarpha macropoda. L. variabilis apresentou maior densidade absoluta (2.568 ind./ha) e relativa $(24,21 \%)$. T. pulchra apresentou a maior dominância absoluta e relativa, com $10,04 \mathrm{~m}^{2} /$ ha e $37,72 \%$, respectivamente. Na estrutura da floresta, destacaram-se as espécies pioneiras. A diversidade $\left(\mathrm{H}^{\prime}=3,330\right.$ nat. ind $\left.^{-1}\right)$ e equabilidade $\left(\mathrm{J}^{\prime}=0,666\right)$ obtidas são equivalentes a áreas de mesma idade. A regeneração natural é uma forma promissora de recuperação ambiental em condições semelhantes, pois permite a formação de uma floresta secundária com elevada riqueza de espécies e densidade de indivíduos, além de erradicar de 91,93 a 100\% das bananeiras anteriormente introduzidas.
\end{abstract}

Palavras-chave: sucessão florestal; restauração passiva; bananicultura; Juréia.

\footnotetext{
Recebido para análise em 13.09.2016. Aceito para publicação em 31.05.2017.

2Instituto Florestal, Rua do Horto, 931, 02377-000, São Paulo, SP, Brasil.

${ }^{3}$ Programa de Pós-graduação em Ciência Ambiental - PROCAM, Instituto de Energia e Ambiente - IEE, Universidade de São Paulo, Av. Prof. Luciano Gualberto, 1289, Cidade Universitária, 05508-010, São Paulo, SP, Brasil.

${ }^{4}$ Autor para correspondência: Claudio de Moura - claudio.moura69@yahoo.com.br
} 


\begin{abstract}
This work described the process of succession of vegetation in natural regeneration of an suppressed forest area for introduction of banana plantation in the Juréia-Itatins Ecological Station after eight years of abandonment of agricultural activities. The floristic and phytosociological surveys were conducted on five plots of $10 \times 25 \mathrm{~m}$, where all individuals of shrub-tree size $\geq 1 \mathrm{~m}$ height where all individuals of shrub-tree size $\geq 1 \mathrm{~m}$ height were collected, the height and perimeter of plants were recorded and the species have been classified in dispersal syndromes and successional groups. The forest structure was analyzed using the usual phytosociology parameters, Shannon diversity index (H') and equability (J'). We sampled 1,440 individuals of 149 species and 59 families, being Melastomataceae (29), Myrtaceae (15), Fabaceae (10) and Rubiaceae (9) the families of greater richness, predominating pioneer and early secondary species (36.91\%) and zoochorous (54.36\%). The species with the highest coverage values were Tibouchina pulchra, Leandra variabilis, Miconia cinnamomifolia and Piptocarpha macropoda. L. variabilis showed higher absolute (2,568 ind./ha) and relative (24.21\%) density. T. pulchra showed the highest absolute and relative dominance, with $10.04 \mathrm{~m}^{2} / \mathrm{ha}$ and $37.72 \%$, respectively. In the forest structure predominated the pioneer species. The diversity $\left(\mathrm{H}^{\prime}=3.330\right.$ nat. ind $\left.^{-1}\right)$ and equability $\left(\mathrm{J}^{\prime}=0.666\right)$ obtained are equivalent to areas of the same age. Natural regeneration is a promising form of environmental recovery in similar conditions, because it allowed the formation of a secondary forest with high species richness and density of individuals, besides eradicating from 91.93 to $100 \%$ of the previously introduced banana trees.
\end{abstract}

Keywords: forest succession; passive restoration; banana plantations; Juréia.

\section{INTRODUÇÃO}

A sucessão de comunidades de plantas é um dos processos ecológicos mais difundidos da ecologia, no qual a mudança na estrutura e composição de espécies, após perturbações naturais ou antrópicas, tem sido usada para produzir e testar muitos conceitos fundamentais e teorias ecológicas (Cadenasso et al., 2008).

Estudando a sucessão de comunidades vegetais após perturbação, Connell e Slatyer (1977) estabeleceram que existem três modelos de sucessão de espécies, as facilitadoras, tolerantes e inibidoras, conforme segue: Facilitadoras - são espécies de início de sucessão que se estabelecem no ambiente e criam as condições adequadas de solo e microclima para as espécies tardias; Tolerantes - são espécies de sucessão tardia que têm mais capacidade do que as de início de sucessão de crescer e se desenvolver com poucos recursos, mesmo na presença de outras espécies; Inibidoras - são espécies de sucessão tardia que não conseguem crescer na presença das iniciais, aparecem mais tarde por terem vida longa e gradualmente vão se desenvolvendo até substituírem as espécies iniciais de sucessão.

Apesar da dificuldade em prever padrões de substituição de espécies, durante a sucessão secundária ocorre uma série de eventos e processos que começam com a colonização inicial do local, avançam por meio do fechamento do dossel, da recuperação de riqueza de espécies, do aumento na área basal e da biomassa, e terminam com o retorno a uma composição de espécies semelhante às condições de sucessão tardia (Guariguata e Ostertag, 2001).

A regeneração natural é um processo de sucessão secundária em nível de comunidade e de ecossistema, sobre uma área florestada que foi desmatada, onde o processo sucessional segue uma progressão de estágios ou fases durante os quais as florestas apresentam enriquecimento gradual de espécies e um aumento em complexidade estrutural e funcional (Chazdon, 2012). 
MOURA, C. de; MANTOVANI, W. Regeneração natural de floresta após oito anos de abandono da bananicultura.

A capacidade de regeneração da vegetação da floresta neotropical é alta se existirem fontes de propágulos e se a intensidade de uso do solo antes do abandono não tiver sido severa (Guariguata e Ostertag, 2001). $\mathrm{Na}$ regeneração natural, até áreas recentemente desmatadas ou pouco degradadas podem ser recuperadas pelos meios locais, ou seja, pelo brotamento das árvores cortadas, assim como pela germinação de sementes presentes na chuva e banco de sementes, ou por meios externos, como fragmentos florestais próximos que funcionam como fontes de sementes, que são importantes para a regeneração da floresta (Ferretti, 2002; Carpanezzi, 2005; Baider et al., 2001), e mesmo pequenos fragmentos bem estruturados podem servir como importantes fontes de sementes para recomposição de áreas degradadas no entorno (Pivello et al., 2006).

Em várias situações em que as perturbações sofridas não tenham sido muito intensas, os processos naturais de regeneração têm-se mostrado mais eficazes em reconstruir o ecossistema do que as interferências planejadas (Durigan et al., 2004). E em algumas delas, a simples remoção dos fatores de degradação e o isolamento da área podem ser suficientes para estimular a sucessão natural (Insernhagen et al., 2010a; Jesus e Rolim, 2005).

O abandono de um local permitindo a recomposição natural da vegetação pela regeneração natural é uma estratégia que tem sido sugerida pela Empresa Brasileira de Pesquisa Agropecuária - EMBRAPA (2003), por favorecer o desenvolvimento de arbustos e árvores que compõem uma floresta secundária, além da estabilização dos solos e a diminuição de erosão.

O retorno espontâneo sem intervenção humana deliberada de um ecossistema degradado a um estado pré-existente, dependente da resiliência e do processo dinâmico de sucessão decorrente de regeneração natural, é denominado restauração passiva (Aronson et al., 2011).

A bananicultura é a atividade econômica mais importante da região do Vale do Ribeira, que é a principal produtora de banana do estado de São Paulo, responsável por mais de $60 \%$ da produção, cuja cultura ocupava 33.855 ha de área produtiva em 2015 (São Paulo, 2008, 2015).
Devido à sua elevada biodiversidade a região do Vale do Ribeira foi considerada como de extrema importância biológica para a conservação da biodiversidade da Mata Atlântica (Brasil, 2000). A Bacia Hidrográfica do Ribeira de Iguape/Litoral Sul concentra 1.163.515 milhões de hectares de vegetação natural remanescente, que corresponde a $53,4 \%$ de sua superfície, representando $4,68 \%$ da vegetação natural do estado de São Paulo, dos quais 35,58\% (414.002 ha) estão inseridos em unidades de conservação (Kronka et al., 2007; Nalon et al., 2008; Xavier et al., 2008).

A Estação Ecológica da Juréia-Itatins - EEJ, criada em meados da década de 1980, foi reclassificada pela Lei $\mathrm{n}^{\circ} 14.982 / 2013$, que alterou os limites da EEJI e criou o Mosaico de Unidades de Conservação Juréia-Itatins - MUCJ, possui área total de 97.213 ha, dos quais 84.425 ha pertencem à EEJI (São Paulo, 2013). A EEJI foi considerada por Mamede et al. (2001) como um dos trechos florestados melhor protegidos e preservados da Mata Atlântica brasileira, que, segundo Myers et al. (2000), é uma das oito áreas mais importantes para conservação da biodiversidade mundial.

O Brasil é considerado um dos países detentores de maior biodiversidade no mundo e, por isso, é responsável por conservar muitas das espécies, ecossistemas naturais e processos biológicos que tornam nosso planeta habitável (Lewinsohn e Prado, 2002). Dessa maneira, as florestas secundárias são importantes por preservarem conjuntos florísticos com considerável riqueza de espécies, muitas raras ou ameaçadas de extinção, cuja existência é um aspecto adicional que valoriza a importância biológica destas florestas (Arzolla et al., 2011).

No ano de 2004, ocorreram diversos desmatamentos em áreas de Floresta Ombrófila Densa para implantação da bananicultura na região norte da EEJI gerando problemas ambientais e legais para a manutenção desta atividade, na região norte da EEJI, que geraram problemas ambientais e legais para a manutenção desta atividade e demandaram ações de manejo e recuperação das áreas degradadas. 
MOURA, C. de; MANTOVANI, W. Regeneração natural de floresta após oito anos de abandono da bananicultura.

Este trabalho além de descrever a vegetação nativa regenerante em uma área de Floresta Ombrófila Densa Submontana degradada para implantação da bananicultura teve também como objetivo responder as seguintes perguntas: I) A regeneração natural é uma alternativa técnica capaz de recuperar áreas degradadas para implantação da bananicultura? II) A regeneração natural da vegetação é capaz de erradicar as bananeiras introduzidas nas condições estudadas?

\section{MATERIAL E MÉTODOS}

\subsection{Descrição e Histórico da Área de Estudo}

A área estudada localiza-se sob as coordenadas $24^{\circ} 20^{\prime} 40,03$ "S e $47^{\circ} 20^{\prime} 14,74^{\prime \prime} \mathrm{W}$ na localidade denominada Colinas Verdes, município de Miracatu, na região do Vale do Ribeira, no interior da Estação Ecológica Juréia-Itatins (EEJI) na região norte (Figura 1), próxima de remanescentes florestais, onde a vegetação predominante é a Floresta Ombrófila Densa Submontana (Kronka et al., 2007). Entre 2004 a 2009, a EEJI foi alvo de inúmeros desmatamentos para a introdução da monocultura da banana Musa sp. (Musaceae), espécie exótica originária do continente asiático.

A introdução da bananicultura no local ocorreu em 2005 e foi manejada até 2007, quando a área foi abandonada. Após oito anos de regeneração natural, o presente estudo foi iniciado em novembro de 2014, porém o monitoramento de perturbações externas (roçadas, uso do fogo, soltura de gado, entre outras) tem sido realizado na área desde 2008. Para a implantação do bananal, houve a supressão de 4,02 ha, o que equivale a $40.200 \mathrm{~m}^{2}$ de vegetação secundária de Floresta Ombrófila Densa Submontana em estágio médio a avançado de regeneração, conforme estabelecido pelo Conselho Nacional do Meio Ambiente - CONAMA na Resolução CONAMA no 10/1993 (CONAMA, 1993), que resultou na autuação da Polícia Ambiental em 16/02/2006.

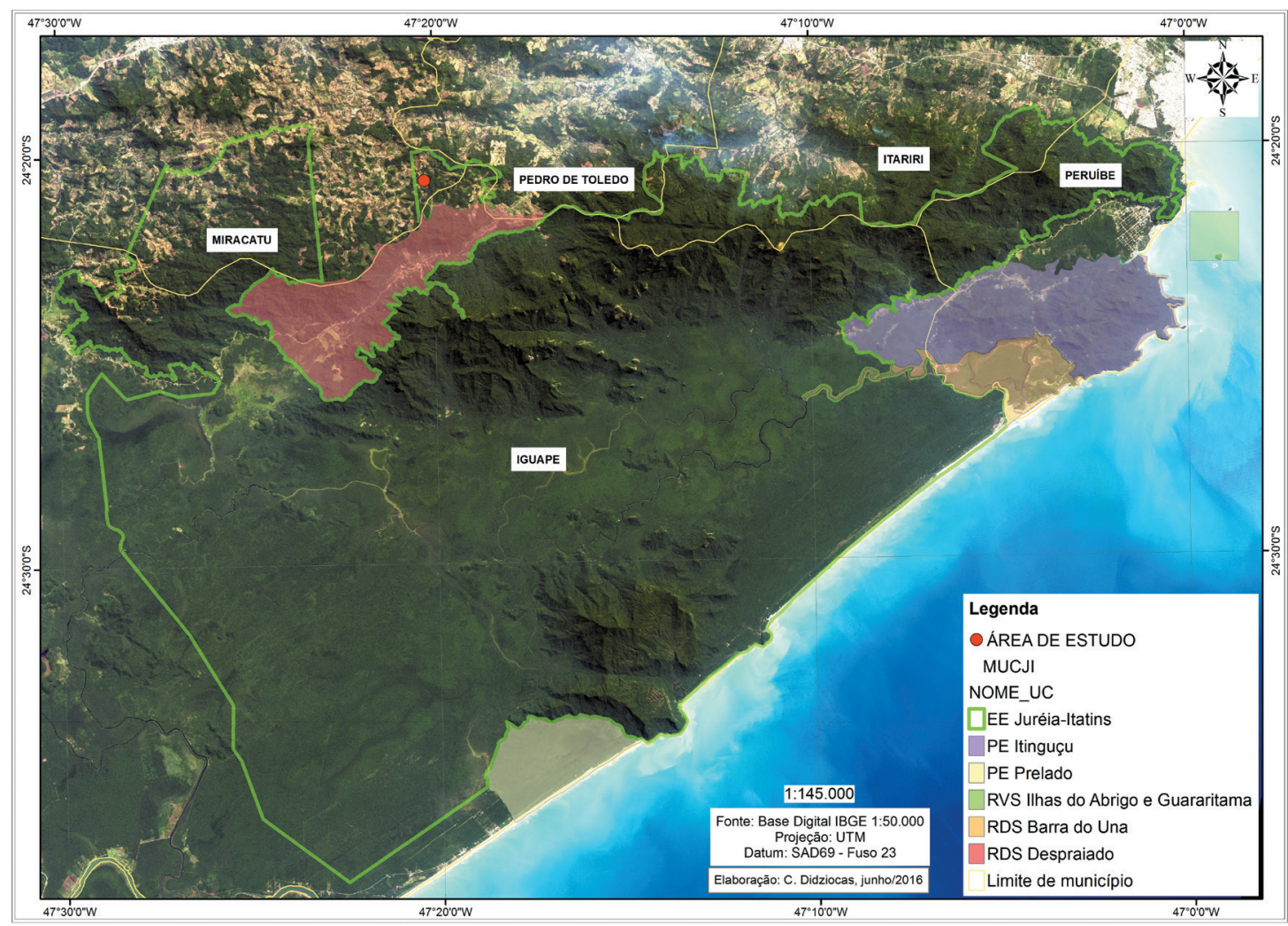

Figura 1. Localização da área de estudo no Mosaico de UCs Juréia-Itatins. (Fonte: acervo EEJI).

Figure 1. Location of the study area in the Juréia-Itatins Conservation Units Mosaic. (Source: EEJI collection). 
MOURA, C. de; MANTOVANI, W. Regeneração natural de floresta após oito anos de abandono da bananicultura.

O clima predominante é do tipo Cfa, segundo o sistema de classificação de Koeppen, com temperatura média anual que varia de 19,6-19,0 ${ }^{\circ} \mathrm{C}$, temperatura média máxima que varia de $24,6-24,2{ }^{\circ} \mathrm{C}$ e pluviosidade média anual que varia de 2.000-2.200 mm (Tarifa, 2004).

Do ponto de vista geomorfológico e geológico, a área estudada situa-se na unidade de Morros e Serras que se estende por uma faixa de direção E-W, com cerca de $50 \mathrm{~km}$ de comprimento e $10 \mathrm{~km}$ de largura; na área de estudo, a unidade de relevo é denominada localmente como Serra do Bananal (na porção oeste), onde predominam rochas gnáissico-migmatíticas (Souza e Souza, 2004).

Segundo Morrone (2001), do ponto de vista biogeográfico, a Juréia situa-se na região Neotropical, na subregião Paranaense, na Província da Floresta Atlântica Brasileira.

\subsection{Estudo Florístico e Fitossociológico}

A caracterização da vegetação na área degradada foi feita por meio de levantamentos de campo com coleta de material botânico realizado em 13 expedições que ocorreram no período de 10 de novembro de 2014 a 19 de outubro de 2015 .

Para o estudo fitossociológico foi utilizado o método de parcelas (Mueller-Dombois e Ellenberg, 1974), em que foi feito um bloco único de $40 \times 100$ metros subdivididos em 16 parcelas de 10 x 25 metros, das quais cinco parcelas foram sorteadas ao acaso, visando amostrar ao máximo a provável heterogeneidade da vegetação regenerante, e posteriormente instaladas para realização do estudo, conforme Figura 2. As cinco parcelas de $10 \times 25 \mathrm{~m}$ totalizaram $1.250 \mathrm{~m}^{2}$, ou seja, 0,125 ha de área total.

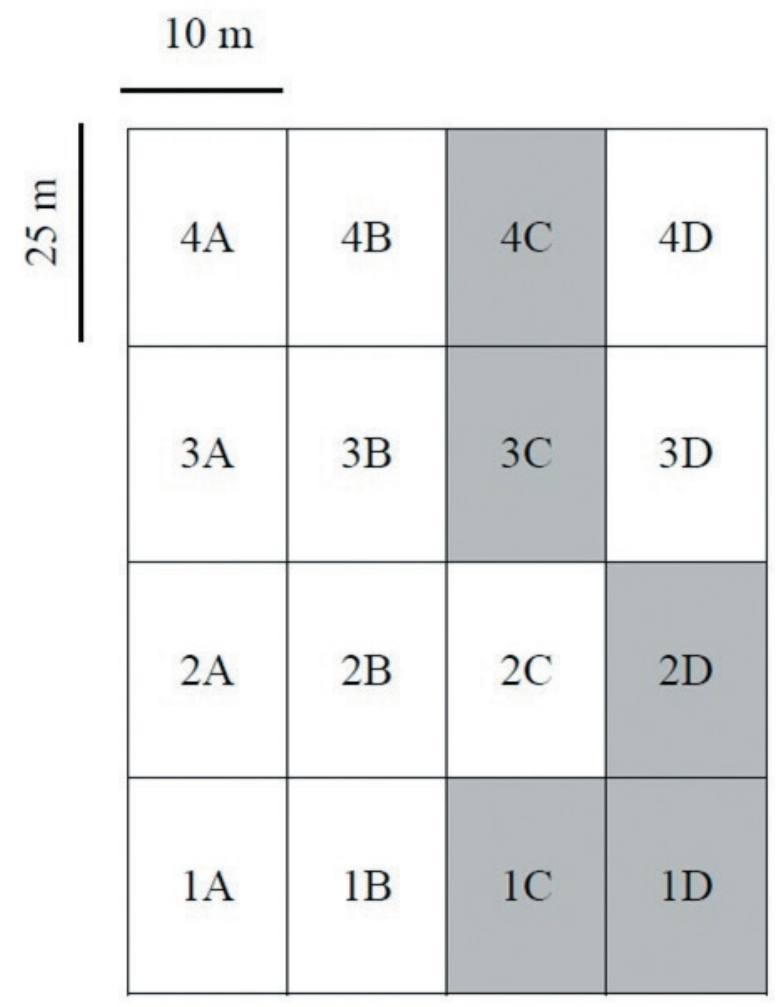

Figura 2. Parcelas sorteadas da área estudada.

Figure 2. Plots drawn from study area. 
Todos os indivíduos lenhosos de porte arbustivo-arbóreo com altura $\geq 1$ metro, férteis ou não, foram amostrados, numerados e etiquetados com fichas de lona plástica afixadas com fitilho de plástico. Para cada indivíduo foi anotada a forma de vida, a circunferência do caule a 1,3 m do solo, ou seja, à altura do peito (CAP) e foi procedida a identificação das espécies em campo, sempre que possível. No caso dos arbustos, arbustos escandentes e indivíduos arbóreos jovens menores que $1,3 \mathrm{~m}$ de altura, a CAP foi medida antes da porção terminal do caule.

As formas de vida consideradas neste trabalho foram arbusto, arbusto-escandente, arvoreta, árvore e feto arborescente, baseadas em Instituto Brasileiro de Geografia e Estatística - IBGE (2012), Sobral e Jarenkow (2006) e Prado e Sylvestre (2010). Por não terem porte arbustivo-arbóreo e por não se enquadrarem nos critérios estabelecidos no estudo, as bananeiras Musa sp. não foram amostradas; porém, todos os indivíduos presentes nas parcelas estudadas foram contabilizados para fins de monitoramento da erradicação da espécie exótica pela regeneração natural.

Para estimar o percentual de erradicação das bananeiras pela regeneração natural dividimos o número de bananeiras remanescentes registradas pelo número de plantas indicadas no espaçamento usual de 2 × $2 \mathrm{~m}$ para cada parcela, conforme recomendações apresentadas por Teixeira et al. (2014).

As coletas de material botânico foram efetuadas com tesoura de poda, tesoura de poda alta e estilingue quando necessário e foram realizadas através de visitas à área selecionada. Todos os indivíduos foram coletados, secos em estufa e processados em herbário, conforme Fidalgo e Bononi (1984).

Os indivíduos lenhosos mortos também foram amostrados, etiquetados e, quando possível, identificados pelo padrão de caule e/ou casca, porém não foram incluídos nas análises fitossociológicas devido à dificuldade de identificação das espécies conforme apontado por Durigan (2009), mas podem servir para indicar a dinâmica da vegetação durante a sucessão florestal, principalmente das espécies de ciclo de vida curto.
Após o processamento dos materiais procedeu-se a identificação botânica das espécies por comparação, consulta a especialistas e com base na literatura especializada. Os materiais férteis identificados serão incorporados ao Herbário Dom Bento José Pickel do Instituto Florestal (SPSF).

As espécies foram categorizadas conforme as síndromes de dispersão dos propágulos: Anemocoria, Autocoria e Zoocoria, propostas por Pijl (1969), e grupos sucessionais: pioneiras (P), secundárias iniciais $(\mathrm{Si})$ e secundárias tardias $(\mathrm{St})$ de acordo com Budowski (1965), Gandolfi et al. (1995), Arzolla (2002) e Catharino (2006), além das espécies de sub-bosque (SB), que têm todo o seu ciclo de vida no interior da floresta na sombra de outras árvores e nunca alcançam o dossel (Tabarelli et al., 1993). As plantas cuja identificação não foi possível foram denominadas "não classificadas" (nc).

Os parâmetros fitossociológicos considerados foram: densidade e dominância, tanto absoluta quanto relativa, além do valor de cobertura (VC), propostos por Mueller-Dombois e Ellenberg (1974), o índice de diversidade de Shannon (H') e equabilidade (J') (Pielou, 1975). Além do Índice de Morisita Padronizado (Ip) (Morisita, 1962 modificado por Smith-Gill, 1975), para análise do padrão de distribuição espacial. Os padrões de distribuição espacial considerados foram os definidos por Matteucci e Colma (1982): aleatório, agregado e regular. Os cálculos foram realizados através do Programa Fitopac (Shepherd, 2010).

A frequência é um parâmetro fitossociológico que sofre muita influência do tamanho da área amostral (Martins, 1991) que resulta em uma supervalorização da frequência relativa (FR) e consequentemente do valor de importância (VI), que é composto pela soma dos valores da densidade relativa, dominância relativa e frequência relativa, desse modo, neste estudo não consideramos os cálculos das frequências relativas e absolutas, assim como do valor de importância. As espécies de angiospermas foram listadas de acordo com a classificação das famílias reconhecidas pelo Angiosperm Phylogeny Group (APG IV, 2016). Para a conferência dos gêneros, sinonímias e descritores foi consultado o site da Lista de Espécies da Flora Brasileira (Forzza et al., 2016). Os fetos arborescentes foram classificados de acordo com Prado e Sylvestre (2016). 
MOURA, C. de; MANTOVANI, W. Regeneração natural de floresta após oito anos de abandono da bananicultura.

\section{RESULTADOS}

\subsection{Indivíduos Registrados na Área Estudada}

Foram registrados 1.444 indivíduos, sendo 118 mortos em pé, dos quais 57 $(48,30 \%)$ foram reconhecidos pelo padrão do caule e/ou casca, o que permitiu identificar 18 indivíduos de Trema micrantha (Cannabaceae), 13 de Leandra variabilis (Melastomataceae), 11 de Cecropia sp. (Urticaceae), seis de Tibouchina pulchra (Melastomataceae), um de Myrsine sp. (Primulaceae), cinco indivíduos de Melastomataceae e três de Cyatheaceae.

$\mathrm{Na}$ área de estudo, foram observados 14 indivíduos de Musa sp. remanescentes do plantio, com cerca de 1 metro de altura, além de indivíduos de outras espécies exóticas, tais como três indivíduos de cafeeiro (Coffea sp.) e um limoeiro (Citrus sp.), também remanescentes das plantas introduzidas pelos agricultores no local.

\subsection{Estudo Florístico}

Foram registrados 1.326 indivíduos vivos, pertencentes a 59 famílias botânicas e distribuídos em 74 gêneros, 149 espécies, dentre as quais 19 foram identificadas no nível de família e 18 de gênero. Não foi possível a identificação em dezessete plantas devido à dificultade de coleta de material e, portanto, foram consideradas indeterminadas (Tabela 1)

Tabela 1. Espécies regenerantes registradas na região das Colinas Verdes, Estação Ecológica Juréia-Itatins, MiracatuSP. Número de indivíduos (Ni). Grupos sucessionais (Gs): Pioneira (P), Secundária inicial (Si), Secundária tardia (St) e Sub-bosque (SB). Síndrome de dispersão (Sd): Autocoria (Aut), Anemocoria (Ane), Zoocoria (Zoo) e não classificada (nc).

Table 1. Regenerating species registered in Colinas Verdes region, Juréia-Itatins Ecological Station, Miracatu-SP. Number of individuals (Ni). Sucessional groups (Gs): Pioneer (P), secondary (Si), late Secondary (St) and understorey (SB). Dispersion syndrome (Sd): Viviparous (Aut), Anemochory (Ane), Zoochory (Zoo) and not classified (nc).

\begin{tabular}{|c|c|c|c|c|}
\hline Família & Espécie & NI & Gs & $\mathrm{Sd}$ \\
\hline \multirow[t]{3}{*}{ Annonaceae } & Annona dolabripetala Raddi & 2 & $\mathrm{St}$ & Zoo \\
\hline & Annona sp.1 & 1 & $\mathrm{St}$ & Zoo \\
\hline & Xylopia langsdorfiana A.St.-Hil. \& Tul. & 1 & St & Zoo \\
\hline Apocynaceae & Tabernaemontana catharinensis A.DC. & 1 & St & Zoo \\
\hline Arecaceae & Astrocaryum aculeatissimum (Schott) Burret & 1 & SB & Zoo \\
\hline \multirow[t]{6}{*}{ Asteraceae } & Austroeupatorium inulaefolium (Kunth) R.M.King \& H.Rob. & 1 & $\mathrm{P}$ & Ane \\
\hline & Critoniopsis quinqueflora (Less.) H.Rob. & 1 & $\mathrm{P}$ & Ane \\
\hline & Piptocarpha macropoda (DC.) Baker & 37 & $\mathrm{P}$ & Ane \\
\hline & Vernonanthura discolor (Spreng.) H.Rob. & 10 & $\mathrm{P}$ & Ane \\
\hline & Vernonanthura puberula (Less.) H.Rob. & 6 & $\mathrm{P}$ & Ane \\
\hline & Vernonia sp. & 1 & $\mathrm{P}$ & Ane \\
\hline Bignoniaceae & Bignoniaceae 1 & 1 & $\mathrm{nc}$ & nc \\
\hline Canellaceae & Cinnamodendron dinisii Schwacke & 1 & St & Zoo \\
\hline Cannabaceae & Trema micrantha $(\mathrm{L}$.$) Blume$ & 20 & $\mathrm{P}$ & Zoo \\
\hline \multirow[t]{2}{*}{ Celastraceae } & Cheiloclinium sp. & 1 & SB & Zoo \\
\hline & Maytenus sp.1 & 1 & SB & Zoo \\
\hline Clusiaceae & Garcinia gardneriana (Planch. \& Triana) Zappi & 1 & SB & Zoo \\
\hline
\end{tabular}

continua to be continued 
MOURA, C. de; MANTOVANI, W. Regeneração natural de floresta após oito anos de abandono da bananicultura.

continuação - Tabela 1

continuation - Table 1

\begin{tabular}{|c|c|c|c|c|}
\hline Família & Espécie & NI & Gs & $\mathrm{Sd}$ \\
\hline Cyatheaceae & Cyatheaceae & 13 & SB & Ane \\
\hline \multirow[t]{2}{*}{ Elaeocarpaceae } & Sloanea guianensis (Aubl.) Benth. & 3 & $\mathrm{St}$ & Ane \\
\hline & Sloanea hirsuta (Schott) Planch. ex Benth. & 5 & $\mathrm{St}$ & Ane \\
\hline \multirow[t]{5}{*}{ Euphorbiaceae } & Acalypha diversifolia Jacq. & 1 & nc & $\mathrm{nc}$ \\
\hline & Alchornea triplinervia (Spreng.) Müll.Arg. & 24 & $\mathrm{Si}$ & Zoo \\
\hline & Aparisthmium cordatum (A.Juss.) Baill. & 22 & $\mathrm{Si}$ & Aut \\
\hline & Maprounea guianensis Aubl. & 24 & $\mathrm{Si}$ & Aut \\
\hline & Tetrorchidium rubrivenium Poepp. & 7 & $\mathrm{Si}$ & Zoo \\
\hline \multirow[t]{10}{*}{ Fabaceae } & Copaifera trapezifolia Hayne & 1 & $\mathrm{St}$ & Zoo \\
\hline & Dahlstedtia pinnata (Benth.) Malme & 1 & $\mathrm{Si}$ & Aut \\
\hline & Dalbergia frutescens (Vell.) Britton & 1 & $\mathrm{Si}$ & Ane \\
\hline & Dioclea sp.1 & 3 & $\mathrm{nc}$ & $\mathrm{nc}$ \\
\hline & Fabaceae 1 & 1 & nc & $\mathrm{nc}$ \\
\hline & Machaerium brasiliense Vogel & 1 & $\mathrm{St}$ & Ane \\
\hline & Machaerium cantarellianum Hoehne & 1 & $\mathrm{St}$ & Ane \\
\hline & Machaerium oblongifolium Vogel & 1 & St & Ane \\
\hline & Ormosia arborea (Vell.) Harms & 1 & $\mathrm{St}$ & Zoo \\
\hline & Senna multijuga (Rich.) H.S.Irwin \& Barneby & 3 & $\mathrm{P}$ & Auto \\
\hline Humiriaceae & Vantanea compacta (Schnizl.) Cuatrec. & 2 & St & Zoo \\
\hline Lamiaceae & Aegiphila integrifolia (Jacq.) Moldenke & 2 & $\mathrm{P}$ & Zoo \\
\hline \multirow[t]{3}{*}{ Lauraceae } & Endlicheria paniculata (Spreng.) J.F.Macbr. & 1 & SB & Zoo \\
\hline & Nectandra oppositifolia Nees & 6 & $\mathrm{Si}$ & Zoo \\
\hline & Ocotea sp. & 1 & $\mathrm{nc}$ & $\mathrm{nc}$ \\
\hline Lecythidaceae & Cariniana estrellensis (Raddi) Kuntze & 1 & $\mathrm{St}$ & Ane \\
\hline Loganiaceae & Strychnos trinervis (Vell.) Mart. & 2 & $\mathrm{nc}$ & $\mathrm{nc}$ \\
\hline Malpighiaceae & Heteropterys aenea Griseb. & 1 & $\mathrm{nc}$ & $\mathrm{nc}$ \\
\hline \multirow[t]{9}{*}{ Melastomataceae } & Huberia aff. nettoana Brade & 1 & $\mathrm{nc}$ & $\mathrm{nc}$ \\
\hline & Leandra melastomoides Raddi & 31 & $\mathrm{P}$ & Zoo \\
\hline & Leandra variabilis Raddi & 321 & $\mathrm{P}$ & Zoo \\
\hline & Leandra sp.1 & 7 & $\mathrm{nc}$ & $\mathrm{nc}$ \\
\hline & Leandra sp.2 & 1 & $\mathrm{nc}$ & $\mathrm{nc}$ \\
\hline & Miconia cabucu Hoehne & 19 & $\mathrm{Si}$ & Zoo \\
\hline & Miconia cinnamomifolia (DC.) Naudin & 136 & $\mathrm{Si}$ & Zoo \\
\hline & Miconia cubatanensis Hoehne & 1 & $\mathrm{Si}$ & Zoo \\
\hline & Miconia discolor DC. & 45 & $\mathrm{P}$ & Zoo \\
\hline
\end{tabular}

to be continued 
MOURA, C. de; MANTOVANI, W. Regeneração natural de floresta após oito anos de abandono da bananicultura.

continuação - Tabela 1

continuation - Table 1

\begin{tabular}{|c|c|c|c|c|}
\hline Família & Espécie & NI & Gs & $\mathrm{Sd}$ \\
\hline & Miconia latecrenata (DC.) Naudin & 9 & $\mathrm{P}$ & Zoc \\
\hline & Miconia pusilliflora (DC.) Naudin & 1 & SB & Zoc \\
\hline & Miconia sp.2 & 1 & $\mathrm{nc}$ & $\mathrm{nc}$ \\
\hline & Ossaea amygdaloides (DC.) Triana & 3 & $\mathrm{P}$ & Zoc \\
\hline & Ossaea sanguinea Cogn. & 11 & $\mathrm{P}$ & Zoc \\
\hline & Tibouchina pulchra Cogn. & 170 & $\mathrm{P}$ & An \\
\hline & Melastomataceae 1 & 1 & $\mathrm{nc}$ & $\mathrm{nc}$ \\
\hline & Melastomataceae 2 & 1 & $\mathrm{nc}$ & $\mathrm{nc}$ \\
\hline & Melastomataceae 3 & 1 & nc & $\mathrm{nc}$ \\
\hline & Melastomataceae 4 & 1 & nc & $\mathrm{nc}$ \\
\hline & Melastomataceae 5 & 1 & nc & $\mathrm{nc}$ \\
\hline & Melastomataceae 6 & 1 & $\mathrm{nc}$ & $\mathrm{nc}$ \\
\hline & Melastomataceae 7 & 1 & nc & $\mathrm{nc}$ \\
\hline & Melastomataceae 8 & 1 & nc & $\mathrm{nc}$ \\
\hline & Melastomataceae 9 & 1 & nc & $\mathrm{nc}$ \\
\hline & Melastomataceae 10 & 1 & nc & $\mathrm{nc}$ \\
\hline & Melastomataceae 11 & 1 & $\mathrm{nc}$ & $\mathrm{nc}$ \\
\hline & Melastomataceae 12 & 1 & $\mathrm{nc}$ & $\mathrm{nc}$ \\
\hline & Melastomataceae 13 & 1 & $\mathrm{nc}$ & $\mathrm{nc}$ \\
\hline & Melastomataceae 14 & 1 & nc & $\mathrm{nc}$ \\
\hline Meliaceae & Guarea macrophylla Vahl & 1 & SB & Zoc \\
\hline \multirow[t]{2}{*}{ Monimiaceae } & Mollinedia schottiana (Spreng.) Perkins & 11 & SB & Zoc \\
\hline & Siparuna guianensis (Spreng.) A.DC. & 1 & $\mathrm{Si}$ & Zoc \\
\hline \multirow[t]{2}{*}{ Moraceae } & Ficus gomelleira Kunth & 1 & $\mathrm{Si}$ & Zoc \\
\hline & Sorocea hilarii Gaudich. & 1 & $\mathrm{St}$ & Zoc \\
\hline Myristicaceae & Virola bicuhyba (Schott ex Spreng.) Warb. & 1 & $\mathrm{St}$ & Zoc \\
\hline \multirow[t]{9}{*}{ Myrtaceae } & Calyptranthes grandifolia O.Berg & 2 & $\mathrm{St}$ & Zoc \\
\hline & Eugenia cerasiflora Miq. & 1 & $\mathrm{St}$ & Zoc \\
\hline & Eugenia excelsa O.Berg & 3 & $\mathrm{St}$ & Zoc \\
\hline & Eugenia macahensis O.Berg & 1 & $\mathrm{St}$ & Zoc \\
\hline & Eugenia prasina O.Berg & 12 & $\mathrm{St}$ & Zoc \\
\hline & Eugenia stigmatosa DC. & 1 & St & Zoc \\
\hline & Eugenia sp.1 & 1 & nc & $\mathrm{nc}$ \\
\hline & Eugenia sp.2 & 3 & nc & $\mathrm{nc}$ \\
\hline & Myrcia splendens (Sw.) DC. & 1 & St & Zoc \\
\hline
\end{tabular}

to be continued 
MOURA, C. de; MANTOVANI, W. Regeneração natural de floresta após oito anos de abandono da bananicultura.

continuação - Tabela 1

continuation - Table 1

\begin{tabular}{|c|c|c|c|c|}
\hline Família & Espécie & NI & Gs & $\mathrm{Sd}$ \\
\hline & Myrcia tijucensis Kiaersk. & 1 & St & Zoo \\
\hline & Myrciaria sp.1 & 1 & $\mathrm{Si}$ & Zoo \\
\hline & Myrtaceae 1 & 1 & $\mathrm{Si}$ & Zoo \\
\hline \multirow[t]{3}{*}{ Nyctaginaceae } & Guapira hirsuta (Choisy) Lundell & 4 & $\mathrm{Si}$ & Zoo \\
\hline & Guapira nitida (Mart. ex J.A.Schmidt) Lundell & 14 & $\mathrm{Si}$ & Zoo \\
\hline & Guapira opposita (Vell.) Reitz & 21 & $\mathrm{Si}$ & Zoo \\
\hline Olacaceae & Heisteria silvianii Schwacke & 5 & St & Zoo \\
\hline Peraceae & Pera glabrata (Schott) Poepp. ex Baill. & 1 & $\mathrm{Si}$ & Zoo \\
\hline Phyllantaceae & Hyeronima alchorneoides Allemão & 51 & $\mathrm{Si}$ & Auto \\
\hline \multirow[t]{2}{*}{ Piperaceae } & Piper aduncum L. & 1 & $\mathrm{P}$ & Zoo \\
\hline & Piper caldense C.DC. & 2 & $\mathrm{P}$ & Zoo \\
\hline \multirow[t]{3}{*}{ Primulaceae } & Myrsine coriacea (Sw.) R.Br. ex Roem. \& Schult. & 50 & $\mathrm{P}$ & Zoo \\
\hline & Myrsine umbellata Mart. & 1 & $\mathrm{Si}$ & Zoo \\
\hline & Myrsine sp. & 3 & $\mathrm{P}$ & Zoo \\
\hline Rhamnaceae & Rhamnus sphaerosperma $\mathrm{Sw}$. & 1 & St & Zoo \\
\hline \multirow[t]{8}{*}{ Rubiaceae } & Coffea sp.* & 3 & $\mathrm{nc}$ & $\mathrm{nc}$ \\
\hline & Posoqueria acutifolia Mart. & 1 & $\mathrm{Si}$ & Zoo \\
\hline & Posoqueria latifolia (Rudge) Schult. & 9 & $\mathrm{Si}$ & Zoo \\
\hline & Psychotria carthagenensis Jacq. & 1 & SB & Zoo \\
\hline & Psychotria nemorosa Gardner & 4 & SB & Zoo \\
\hline & Psychotria sp. & 1 & SB & Zoo \\
\hline & Rudgea recurva Müll.Arg. & 13 & SB & Zoo \\
\hline & Rubiaceae 1 & 1 & $\mathrm{nc}$ & $\mathrm{nc}$ \\
\hline Rutaceae & Citrus sp.* & 1 & $\mathrm{nc}$ & $\mathrm{nc}$ \\
\hline Sabiaceae & Meliosma sellowii Urb. & 5 & $\mathrm{Si}$ & Zoo \\
\hline Salicaceae & Casearia gossypiosperma Briq. & 4 & St & Zoo \\
\hline Sapindaceae & Cupania oblongifolia Mart. & 7 & $\mathrm{Si}$ & Zoo \\
\hline \multirow[t]{3}{*}{ Sapotaceae } & Chrysophyllum flexuosum Mart. & 3 & St & Zoo \\
\hline & Ecclinusa ramiflora Mart. & 2 & $\mathrm{St}$ & Zoo \\
\hline & Pouteria beaurepairei (Glaz. \& Raunk.) Baehni & 1 & St & Zoo \\
\hline \multirow[t]{4}{*}{ Solanaceae } & Solanum argenteum Dunal & 2 & $\mathrm{Si}$ & Zoo \\
\hline & Solanum cernuum Vell. & 7 & $\mathrm{P}$ & Zoo \\
\hline & Solanum stipulatum Vell. & 5 & $\mathrm{Si}$ & Zoo \\
\hline & Solanum swartzianum Roem. \& Schult. & 8 & $\mathrm{P}$ & Zoo \\
\hline Symplocaceae & Symplocos falcata Brand & 1 & $\mathrm{St}$ & Zoo \\
\hline
\end{tabular}

to be continued 
MOURA, C. de; MANTOVANI, W. Regeneração natural de floresta após oito anos de abandono da bananicultura.

continuação - Tabela 1

continuation - Table 1

\begin{tabular}{|c|c|c|c|c|}
\hline Família & Espécie & NI & Gs & $\mathrm{Sd}$ \\
\hline \multirow[t]{5}{*}{ Urticaceae } & Cecropia glaziovii Snethl. & 11 & $\mathrm{P}$ & Zoo \\
\hline & Cecropia pachystachya Trécul & 8 & $\mathrm{P}$ & Zoo \\
\hline & Cecropia sp. & 4 & $\mathrm{P}$ & Zoo \\
\hline & Urera nitida (Vell.) P.Brack & 12 & $\mathrm{P}$ & Zoo \\
\hline & Urticaceae 1 & 1 & $\mathrm{nc}$ & $\mathrm{nc}$ \\
\hline Indeterminada 1 & Indeterminada 1 & 1 & $\mathrm{nc}$ & $\mathrm{nc}$ \\
\hline Indeterminada 2 & Indeterminada 2 & 1 & $\mathrm{nc}$ & $\mathrm{nc}$ \\
\hline Indeterminada 3 & Indeterminada 3 & 1 & nc & $\mathrm{nc}$ \\
\hline Indeterminada 4 & Indeterminada 4 & 1 & $\mathrm{nc}$ & $\mathrm{nc}$ \\
\hline Indeterminada 5 & Indeterminada 5 & 1 & $\mathrm{nc}$ & $\mathrm{nc}$ \\
\hline Indeterminada 6 & Indeterminada 6 & 1 & $\mathrm{nc}$ & $\mathrm{nc}$ \\
\hline Indeterminada 7 & Indeterminada 7 & 1 & $\mathrm{nc}$ & $\mathrm{nc}$ \\
\hline Indeterminada 8 & Indeterminada 8 & 1 & $\mathrm{nc}$ & $\mathrm{nc}$ \\
\hline Indeterminada 9 & Indeterminada 9 & 1 & $\mathrm{nc}$ & $\mathrm{nc}$ \\
\hline Indeterminada 10 & Indeterminada 10 & 1 & $\mathrm{nc}$ & $\mathrm{nc}$ \\
\hline Indeterminada 11 & Indeterminada 11 & 1 & $\mathrm{nc}$ & $\mathrm{nc}$ \\
\hline Indeterminada 12 & Indeterminada 12 & 1 & $\mathrm{nc}$ & $\mathrm{nc}$ \\
\hline Indeterminada 13 & Indeterminada 13 & 1 & $\mathrm{nc}$ & $\mathrm{nc}$ \\
\hline Indeterminada 14 & Indeterminada 14 & 1 & $\mathrm{nc}$ & $\mathrm{nc}$ \\
\hline Indeterminada 15 & Indeterminada 15 & 1 & $\mathrm{nc}$ & $\mathrm{nc}$ \\
\hline Indeterminada 16 & Indeterminada 16 & 1 & $\mathrm{nc}$ & $\mathrm{nc}$ \\
\hline Indeterminada 17 & Indeterminada 17 & 1 & $\mathrm{nc}$ & nc \\
\hline
\end{tabular}

*Espécie exótica.

*Exotic species.

Os gêneros de maior riqueza foram Eugenia e Miconia com sete espécies cada, Leandra e Solanum (quatro cada), que juntos que juntos totalizam 32 espécies, as quais representam $21,47 \%$ das espécies (Tabela 1 ).

As famílias com as maiores riquezas de espécies foram Melastomataceae (29), Myrtaceae (15), Fabaceae (10), Rubiaceae (nove), Asteraceae (seis), Euphorbiaceae e Urticaceae, (cinco cada), que juntas representam 53,02\% do total de espécies amostradas (Tabela 1; Figura 3).
Os grupos sucessionais predominantes foram as espécies secundárias tardias (St) com $22,82 \%$, seguidas das secundárias iniciais $(\mathrm{Si})$ com 19,46\%, pioneiras (P) com 17,45\% e de sub-bosque (SB) com $8,05 \%$. A classificação não foi possível para $32,21 \%$ das espécies registradas (Tabela 1; Figura 4).

A síndrome de dispersão predominante na amostra foi a zoocoria em $54,36 \%$ das espécies, anemocoria $(10,07 \%)$, autocoria $(3,35 \%)$ e $32,21 \%$ não foram classificados (nc) (Tabela 1; Figura 5). 
MOURA, C. de; MANTOVANI, W. Regeneração natural de floresta após oito anos de abandono da bananicultura.

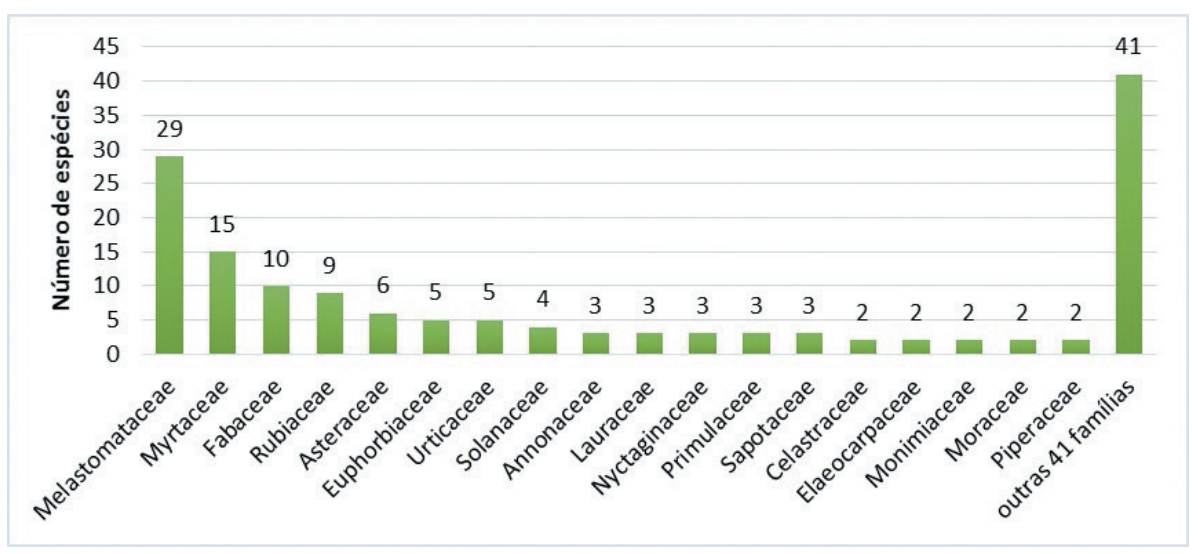

Figura 3. Famílias com maiores riquezas de espécies da área estudada, EEJI, Miracatu-SP.

Figure 3. Families with highest species richness in the studied area, EEJI, Miracatu-SP.

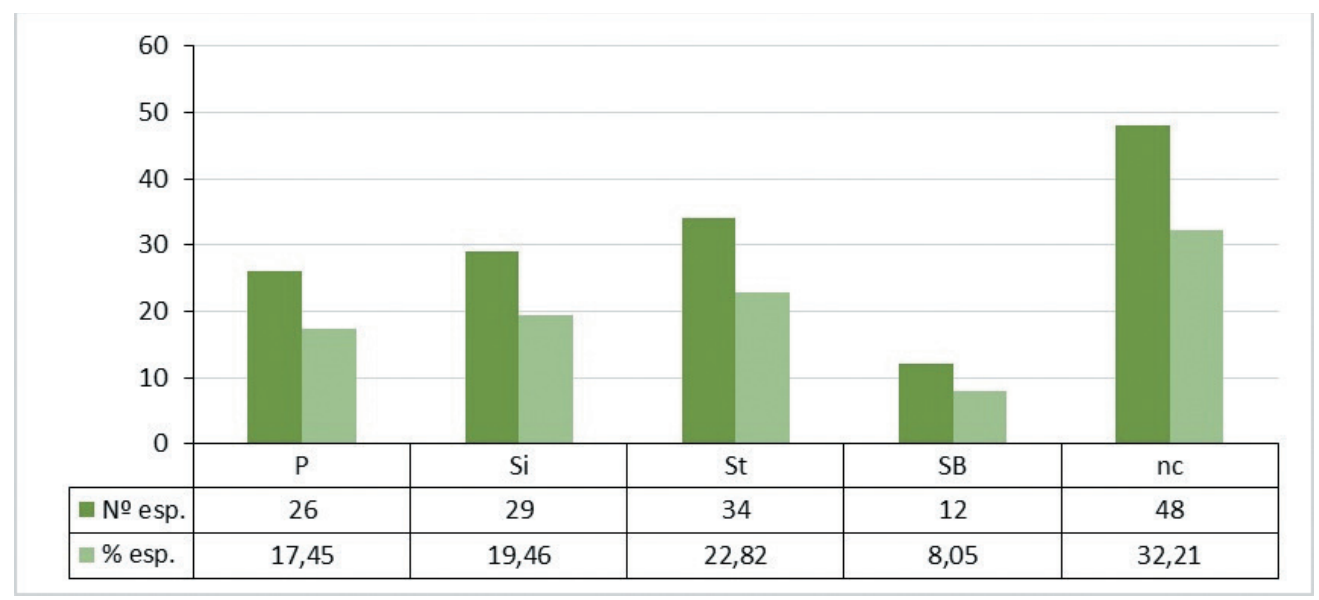

Figura 4. Grupos sucessionais predominantes entre as espécies levantadas na área estudada, EEJI, Miracatu-SP.

Figure 4. Predominant successional groups among the species surveyed in the studied area, EEJ, Miracatu-SP.

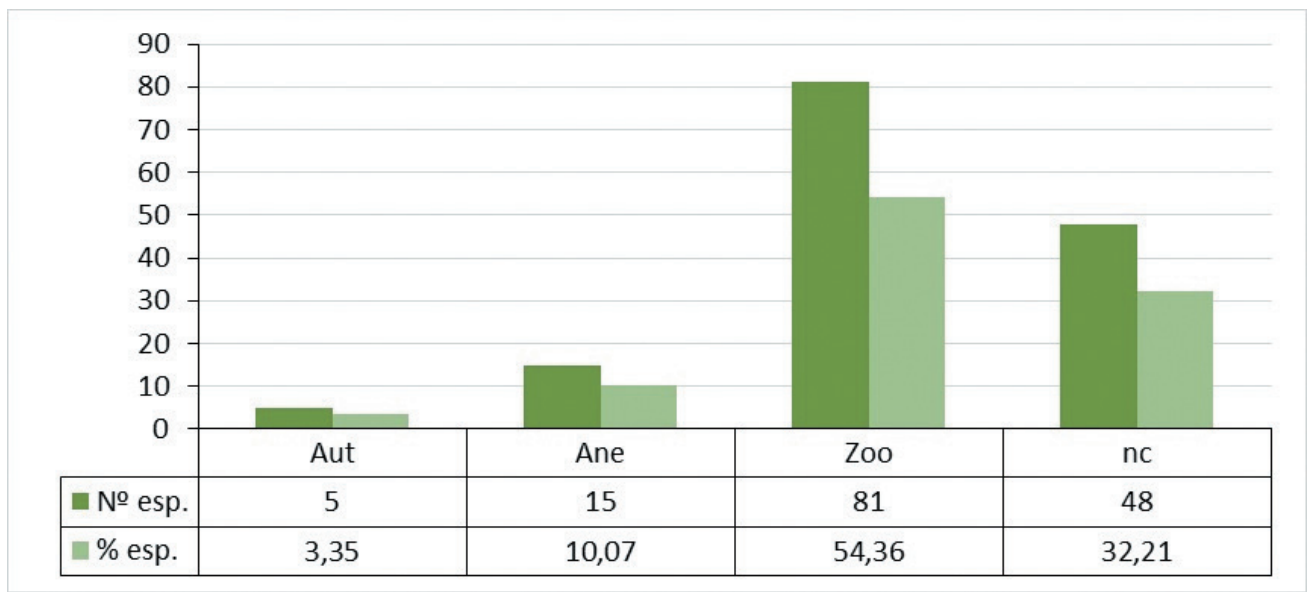

Figura 5. Síndromes de dispersão predominantes entre as espécies levantadas no estudo, EEJI, Miracatu-SP.

Figure 5. Dispersion syndromes predominant among the species surveyed in the study, EEJI, Miracatu-SP. 
MOURA, C. de; MANTOVANI, W. Regeneração natural de floresta após oito anos de abandono da bananicultura.

\subsection{Estudo Fitossociológico}

No estudo foram amostrados 1.326 indivíduos, a Dominância Absoluta total da amostra foi de 26,63 $\mathrm{m}^{2} / \mathrm{ha}$ e a Densidade Absoluta obtida foi de 10.608 ind./ha. $O$ índice de diversidade de Shannon-Wiener calculado para a área de estudo foi $\mathrm{H}^{\prime}=3,330$ nat. ind $^{-1}$ e o valor da equabilidade de Pielou foi $\mathrm{J}^{\prime}=0,666$, conforme características gerais da vegetação regenerante apresentadas na Tabela 2.
O cálculo do Índice de Morisita Padronizado (Ip) obtido foi Ip $=0,503$, assim o padrão de distribuição espacial das espécies é agregado, conforme Matteucci e Colma (1982), pois neste índice, se o valor padronizado for $>0,5$ a distribuição espacial da população será agregada; se for $<-0,5$, a distribuição será uniforme; se estiver entre estes dois valores, será aleatória.

Tabela 2. Características gerais da vegetação regenerante na área de estudo, E.E. Juréia-Itatins.

Table 2. General characteristics of regenerating vegetation in the study area, E.E. Juréia-Itatins.

\begin{tabular}{lc}
\hline Características da vegetação & $\begin{array}{c}\text { Área de estudo } \\
\text { Quantidade }\end{array}$ \\
\hline Número de Famílias & 59 \\
Número de espécies & 149 \\
Área amostrada (m $\left.{ }^{2}\right)$ & 1.250 \\
Densidade (ind./ha) & 10.608 \\
Dominância absoluta (m²/ha) & 26,63 \\
Indivíduos amostrados & 1.444 \\
Indivíduos considerados & 1.326 \\
Indivíduos mortos em pé & 118 \\
Diâmetro máximo (cm) & 24,19 \\
Diâmetro médio (cm) & 3,69 \\
Altura máxima (m) & 19 \\
Altura média (m) & 4,79 \\
Indivíduos com caules múltiplos & 250 \\
Índice Shannon-Wiener & 3,330 \\
Equabilidade & 0,666 \\
\hline
\end{tabular}

Entre os 1.326 indivíduos amostrados, $61(4,6 \%$ dos indivíduos $)$ possuíam altura de 15 a $19 \mathrm{~m}, 162(12,22 \%)$ de 10 a $14,5 \mathrm{~m}$, $198(14,93 \%)$ de 5 a $9,5 \mathrm{~m}$ e $68,25 \%$ deles (905) de 1 a 4,5 m de altura. Entre as 61 árvores com altura de 15 a 19 m, 29 indivíduos (47,54\%) são da espécie Tibouchina pulchra, 12 indivíduos $(19,67 \%)$ de Piptocarpha macropoda e cinco $(8,20 \%)$ da espécie Vernonanthura discolor. Apenas sete indivíduos atingiram 19 metros de altura, sendo um da espécie $P$. macropoda, um de $V$. discolor e cinco de T. pulchra.
A espécie que apresentou o maior diâmetro à altura do peito - DAP do estudo foi Vernonanthura discolor com 24,19 cm, e aquela com maior variação diamétrica foi T. pulchra; uma árvore com três ramificações de $16 \mathrm{~m}$ de altura atingiu o segundo maior DAP da amostra com 22,91 cm (Tabela 3). Na Tabela 3, relacionamos as espécies que apresentaram os indivíduos com os maiores valores de DAP e altura na área estudada. 
MOURA, C. de; MANTOVANI, W. Regeneração natural de floresta após oito anos de abandono da bananicultura.

Tabela 3. Variação do DAP e da altura das espécies levantadas na área estudada, Miracatu, EEJI.

Table 3. Variation of DBH and height of species surveyed in the studied area, Miracatu, EEJI.

\begin{tabular}{lcc}
\hline \multicolumn{1}{c}{ Espécie } & DAP & Altura \\
\hline Vernonanthura discolor & $4,33-24,19 \mathrm{~cm}$ & $8-19 \mathrm{~m}$ \\
Tibouchina pulchra & $0,48-22,91 \mathrm{~cm}$ & $1,2-19 \mathrm{~m}$ \\
Myrsine coriacea & $0,89-20,62 \mathrm{~cm}$ & $2-18 \mathrm{~m}$ \\
Senna multijuga & $2,86-19,75 \mathrm{~cm}$ & $3-8 \mathrm{~m}$ \\
Critoniopsis quinqueflora & $19,74 \mathrm{~cm}$ & $12 \mathrm{~m}$ \\
Piptocarpha macropoda & $0,64-19,10 \mathrm{~cm}$ & $1,3-19 \mathrm{~m}$ \\
Cecropia glaziovii & $5,35-19,10 \mathrm{~cm}$ & $6-15 \mathrm{~m}$ \\
Styrax acuminatus & $17,63 \mathrm{~cm}$ & $14 \mathrm{~m}$ \\
Astrocaryum aculeatissimum & $16,92 \mathrm{~cm}$ & $10 \mathrm{~m}$ \\
Vernonanthura puberula & $15,92 \mathrm{~cm}$ & $1,1-9 \mathrm{~m}$ \\
\hline
\end{tabular}

Ao todo foram levantados 250 indivíduos com caules múltiplos e entre eles as espécies que se destacaram foram Leandra variabilis com até 13 caules, L. melastomoides (sete), Guapira opposita, M. cinnamomifolia e Urera nitida (seis cada), Guapira nitida, Miconia discolor, Senna multijuga e T. pulchra (quatro cada), das quais $60 \%$ são espécies pioneiras. Apenas L. variabilis, com 97 indivíduos com caules múltiplos, representa $30,22 \%$ do total de indivíduos da espécie.
As espécies que apresentaram os maiores Valores de Cobertura (VC) foram Tibouchina pulchra, Leandra variabilis, Miconia cinnamomifolia e Piptocarpha macropoda, responsáveis por $55,69 \%$ do $\mathrm{VC}$, sendo que apenas T. pulchra apresentou $25,27 \%$ e L. variabilis $13,57 \%$ do VC total (Tabela 2; Figura 6). Na Tabela 4, apresentamos os parâmetros fitossociológicos das espécies amostradas na área de estudo.

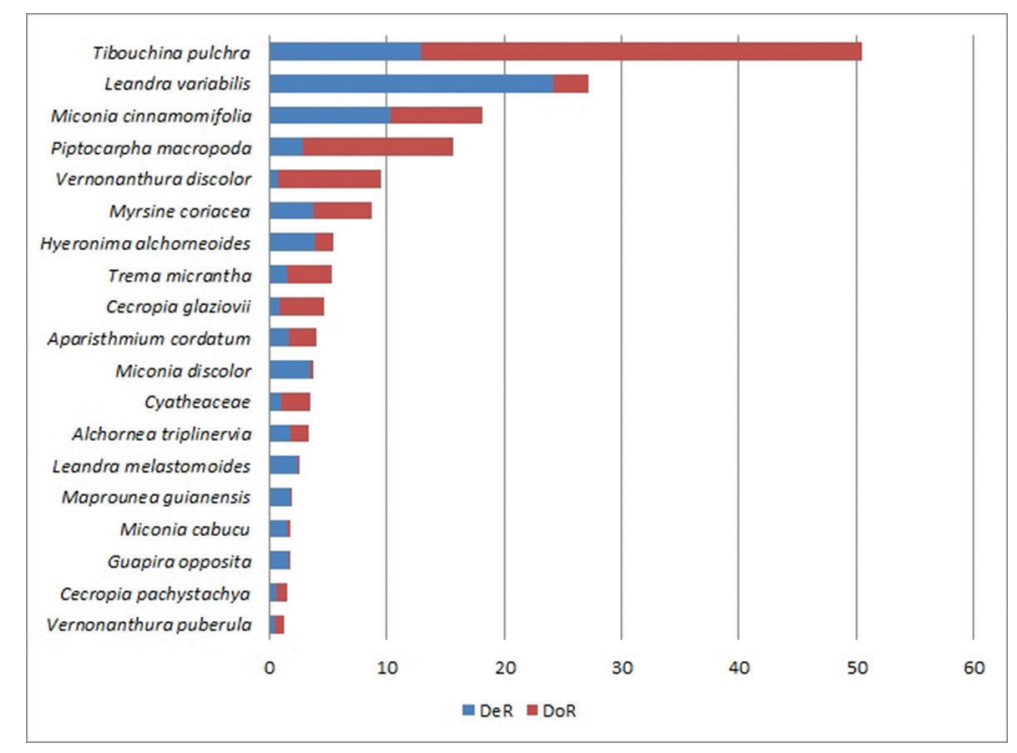

Figura 6. Densidade e dominância relativas das espécies com os maiores Valores de Cobertura da área estudada, EEJI, Miracatu-SP. Valores expressos em porcentagem (\%).

Figure 6. Density and dominance relative of the species with the highest Coverage Values of the studied area, EEJI, Miracatu-SP. Values expressed as percentage $(\%)$. 
MOURA, C. de; MANTOVANI, W. Regeneração natural de floresta após oito anos de abandono da bananicultura.

Tabela 4. Parâmetros fitossociológicos das espécies amostradas na área de estudo no interior da Estação Ecológica Juréia-Itatins, Miracatu, São Paulo. DeA - Densidade Absoluta (ind./ha); DeR - Densidade Relativa (\%); DoA - Dominância Absoluta (m²/ha); DoR - Dominância Relativa (\%); VC - Valor de Cobertura (DeR + DoR) - \%.

Table 4. Phytosociological parameters of the species sampled in the study area inside the Juréia-Itatins Ecological Station, Miracatu, São Paulo. DeA - Absolute Density (ind./ha); DeR - Relative Density (\%); DoA - Absolute Dominance $\left(\mathrm{m}^{2} / \mathrm{ha}\right)$; DoR - Relative Dominance (\%); Value of coverage (DeR + DoR) - \%.

\begin{tabular}{|c|c|c|c|c|c|c|}
\hline Espécie & NI & DeA & DeR & DoA & DoR & $\mathrm{VC}$ \\
\hline Tibouchina pulchra & 170 & 1360 & 12,82 & 10,04 & 37,72 & 50,54 \\
\hline Leandra variabilis & 321 & 2568 & 24,21 & 0,78 & 2,94 & 27,14 \\
\hline Miconia cinnamomifolia & 136 & 1088 & 10,26 & 2,09 & 7,83 & 18,09 \\
\hline Piptocarpha macropoda & 37 & 296 & 2,79 & 3,42 & 12,83 & 15,62 \\
\hline Vernonanthura discolor & 10 & 80 & 0,75 & 2,33 & 8,76 & 9,51 \\
\hline Myrsine coriacea & 50 & 400 & 3,77 & 1,31 & 4,93 & 8,70 \\
\hline Hyeronima alchorneoides & 51 & 408 & 3,85 & 0,40 & 1,51 & 5,35 \\
\hline Trema micrantha & 20 & 160 & 1,51 & 1,01 & 3,79 & 5,30 \\
\hline Cecropia glaziovii & 11 & 88 & 0,83 & 1,00 & 3,77 & 4,60 \\
\hline Miconia discolor & 45 & 360 & 3,39 & 0,09 & 0,33 & 3,73 \\
\hline Aparisthmium cordatum & 22 & 176 & 1,66 & 0,62 & 2,34 & 4,00 \\
\hline Alchornea triplinervia & 24 & 192 & 1,81 & 0,40 & 1,49 & 3,30 \\
\hline Cyatheaceae & 13 & 104 & 0,98 & 0,67 & 2,50 & 3,48 \\
\hline Leandra melastomoides & 31 & 248 & 2,34 & 0,03 & 0,12 & 2,46 \\
\hline Maprounea guianensis & 24 & 192 & 1,81 & 0,03 & 0,12 & 1,93 \\
\hline Miconia cabucu & 19 & 152 & 1,43 & 0,08 & 0,31 & 1,74 \\
\hline Guapira opposita & 21 & 168 & 1,58 & 0,02 & 0,06 & 1,64 \\
\hline Cecropia pachystachya & 8 & 64 & 0,60 & 0,24 & 0,89 & 1,50 \\
\hline Vernonanthura puberula & 6 & 48 & 0,45 & 0,21 & 0,79 & 1,24 \\
\hline Mollinedia schottiana & 11 & 88 & 0,83 & 0,01 & 0,03 & 0,86 \\
\hline Urera nitida & 12 & 96 & 0,9 & 0,04 & 0,15 & 1,06 \\
\hline Rudgea recurva & 13 & 104 & 0,98 & 0,01 & 0,05 & 1,03 \\
\hline Eugenia prasina & 12 & 96 & 0,90 & 0,00 & 0,02 & 0,92 \\
\hline Senna multijuga & 3 & 24 & 0,23 & 0,26 & 0,96 & 1,19 \\
\hline Solanum swartzianum & 8 & 64 & 0,60 & 0,05 & 0,19 & 0,79 \\
\hline Guapira nitida & 14 & 112 & 1,06 & 0,01 & 0,03 & 1,09 \\
\hline Posoqueria latifolia & 9 & 72 & 0,68 & 0,01 & 0,04 & 0,72 \\
\hline Tetrorchidium rubrivenium & 7 & 56 & 0,53 & 0,04 & 0,15 & 0,68 \\
\hline Cupania oblongifolia & 7 & 56 & 0,53 & 0,01 & 0,03 & 0,56 \\
\hline Ossaea sanguinea & 11 & 88 & 0,83 & 0,00 & 0,01 & 0,84 \\
\hline Heisteria silvianii & 5 & 40 & 0,38 & 0,02 & 0,06 & 0,44 \\
\hline Miconia latecrenata & 9 & 72 & 0,68 & 0,02 & 0,07 & 0,75 \\
\hline Solanum cernuит & 7 & 56 & 0,53 & 0,03 & 0,10 & 0,63 \\
\hline
\end{tabular}

to be continued 
MOURA, C. de; MANTOVANI, W. Regeneração natural de floresta após oito anos de abandono da bananicultura.

continuação - Tabela 4

continuation - Table 4

\begin{tabular}{|c|c|c|c|c|c|c|}
\hline Espécie & NI & DeA & DeR & DoA & DoR & $\mathrm{VC}$ \\
\hline Cecropia sp. & 4 & 32 & 0,30 & 0,03 & 0,13 & 0,43 \\
\hline Solanum stipulatum & 5 & 40 & 0,38 & 0,00 & 0,01 & 0,39 \\
\hline Myrsine sp. & 3 & 24 & 0,23 & 0,04 & 0,15 & 0,37 \\
\hline Psychotria nemorosa & 4 & 32 & 0,30 & 0,00 & 0,01 & 0,31 \\
\hline Critoniopsis quinqueflora & 1 & 8 & 0,08 & 0,24 & 0,92 & 0,99 \\
\hline Coffea sp. $1^{*}$ & 3 & 24 & 0,23 & 0,01 & 0,03 & 0,26 \\
\hline Ossaea amygdaloides & 3 & 24 & 0,23 & 0,00 & 0,00 & 0,23 \\
\hline Leandra sp.1 & 7 & 56 & 0,53 & 0,00 & 0,01 & 0,54 \\
\hline Nectandra oppositifolia & 6 & 48 & 0,45 & 0,02 & 0,09 & 0,54 \\
\hline Styrax acuminatus & 1 & 8 & 0,08 & 0,20 & 0,73 & 0,81 \\
\hline Astrocaryum aculeatissimum & 1 & 8 & 0,08 & 0,18 & 0,68 & 0,75 \\
\hline Meliosma sellowii & 5 & 40 & 0,38 & 0,00 & 0,01 & 0,39 \\
\hline Sloanea hirsuta & 5 & 40 & 0,38 & 0,00 & 0,01 & 0,39 \\
\hline Myrcia spectabilis & 4 & 32 & 0,30 & 0,01 & 0,03 & 0,33 \\
\hline Casearia gossypiosperma & 4 & 32 & 0,30 & 0,00 & 0,02 & 0,32 \\
\hline Eugenia sp.2 & 3 & 24 & 0,23 & 0,01 & 0,02 & 0,25 \\
\hline Sloanea guianensis & 3 & 24 & 0,23 & 0,00 & 0,01 & 0,24 \\
\hline Chrysophyllum flexuosum & 3 & 24 & 0,23 & 0,00 & 0,01 & 0,23 \\
\hline Dioclea sp. & 3 & 24 & 0,23 & 0,00 & 0,00 & 0,23 \\
\hline Eugenia excelsa & 3 & 24 & 0,23 & 0,00 & 0,00 & 0,23 \\
\hline Indeterminada 2 & 1 & 8 & 0,08 & 0,13 & 0,48 & 0,56 \\
\hline Vantanea compacta & 2 & 16 & 0,15 & 0,01 & 0,04 & 0,19 \\
\hline Annona dolabripetala & 2 & 16 & 0,15 & 0,00 & 0,02 & 0,17 \\
\hline Ecclinusa ramiflora & 2 & 16 & 0,15 & 0,00 & 0,01 & 0,16 \\
\hline Aegiphila integrifolia & 2 & 16 & 0,15 & 0,00 & 0,01 & 0,16 \\
\hline Marlierea racemosa & 2 & 16 & 0,15 & 0,00 & 0,00 & 0,15 \\
\hline Calyptranthes grandifolia & 2 & 16 & 0,15 & 0,00 & 0,00 & 0,15 \\
\hline Indeterminada 3 & 1 & 8 & 0,08 & 0,09 & 0,34 & 0,41 \\
\hline Guapira hirsuta & 4 & 32 & 0,30 & 0,00 & 0,01 & 0,32 \\
\hline Myrsine umbellata & 1 & 8 & 0,08 & 0,06 & 0,22 & 0,29 \\
\hline Ficus gomelleira & 1 & 8 & 0,08 & 0,04 & 0,15 & 0,23 \\
\hline Melastomataceae 14 & 1 & 8 & 0,08 & 0,05 & 0,18 & 0,25 \\
\hline Indeterminada 4 & 1 & 8 & 0,08 & 0,03 & 0,10 & 0,18 \\
\hline Indeterminada 5 & 1 & 8 & 0,08 & 0,03 & 0,10 & 0,17 \\
\hline Piper caldense & 2 & 16 & 0,15 & 0,00 & 0,01 & 0,16 \\
\hline Solanum argenteum & 2 & 16 & 0,15 & 0,00 & 0,01 & 0,16 \\
\hline Strychnos trinervis & 2 & 16 & 0,15 & 0,00 & 0,00 & 0,15 \\
\hline Tabernaemontana catharinensis & 1 & 8 & 0,08 & 0,02 & 0,07 & 0,14 \\
\hline
\end{tabular}

to be continued 
MOURA, C. de; MANTOVANI, W. Regeneração natural de floresta após oito anos de abandono da bananicultura.

continuação - Tabela 4

continuation - Table 4

\begin{tabular}{|c|c|c|c|c|c|c|}
\hline Espécie & NI & DeA & DeR & DoA & DoR & $\mathrm{VC}$ \\
\hline Rhamnus sphaerosperma & 1 & 8 & 0,08 & 0,01 & 0,05 & 0,13 \\
\hline Indeterminada 11 & 1 & 8 & 0,08 & 0,01 & 0,05 & 0,12 \\
\hline Melastomataceae 9 & 1 & 8 & 0,08 & 0,01 & 0,04 & 0,12 \\
\hline Melastomataceae 4 & 1 & 8 & 0,08 & 0,01 & 0,03 & 0,10 \\
\hline Austroeupatorium inulaefolium & 1 & 8 & 0,08 & 0,01 & 0,02 & 0,10 \\
\hline Indeterminada 1 & 1 & 8 & 0,08 & 0,01 & 0,02 & 0,10 \\
\hline Eugenia sp.1 & 1 & 8 & 0,08 & 0,01 & 0,02 & 0,10 \\
\hline Symplocos falcata & 1 & 8 & 0,08 & 0,01 & 0,02 & 0,10 \\
\hline Maytenus sp. & 1 & 8 & 0,08 & 0,00 & 0,02 & 0,09 \\
\hline Virola bicuhyba & 1 & 8 & 0,08 & 0,00 & 0,01 & 0,09 \\
\hline Myrcia splendens & 1 & 8 & 0,08 & 0,00 & 0,01 & 0,09 \\
\hline Siparuna guianensis & 1 & 8 & 0,08 & 0,00 & 0,01 & 0,09 \\
\hline Myrcia tijucensis & 1 & 8 & 0,08 & 0,00 & 0,01 & 0,08 \\
\hline Machaerium cantarellianum & 1 & 8 & 0,08 & 0,00 & 0,01 & 0,08 \\
\hline Guarea macrophylla & 1 & 8 & 0,08 & 0,00 & 0,01 & 0,08 \\
\hline Endlicheria paniculata & 1 & 8 & 0,08 & 0,00 & 0,01 & 0,08 \\
\hline Leandra sp.2 & 1 & 8 & 0,08 & 0,00 & 0,01 & 0,08 \\
\hline Dahlstedtia pinnata & 1 & 8 & 0,08 & 0,00 & 0,01 & 0,08 \\
\hline Vernonia sp. & 1 & 8 & 0,08 & 0,00 & 0,01 & 0,08 \\
\hline Melastomataceae 1 & 1 & 8 & 0,08 & 0,00 & 0,01 & 0,08 \\
\hline Indeterminada 17 & 1 & 8 & 0,08 & 0,00 & 0,01 & 0,08 \\
\hline Annona sp.1 & 1 & 8 & 0,08 & 0,00 & 0,00 & 0,08 \\
\hline Indeterminada 6 & 1 & 8 & 0,08 & 0,00 & 0,00 & 0,08 \\
\hline Myrciaria sp.1 & 1 & 8 & 0,08 & 0,00 & 0,00 & 0,08 \\
\hline Eugenia cerasiflora & 1 & 8 & 0,08 & 0,00 & 0,00 & 0,08 \\
\hline Melastomataceae 8 & 1 & 8 & 0,08 & 0,00 & 0,00 & 0,08 \\
\hline Machaerium brasiliense & 1 & 8 & 0,08 & 0,00 & 0,00 & 0,08 \\
\hline Piper aduncum & 1 & 8 & 0,08 & 0,00 & 0,00 & 0,08 \\
\hline Posoqueria acutifolia & 1 & 8 & 0,08 & 0,00 & 0,00 & 0,08 \\
\hline Melastomataceae 5 & 1 & 8 & 0,08 & 0,00 & 0,00 & 0,08 \\
\hline Ormosia arborea & 1 & 8 & 0,08 & 0,00 & 0,00 & 0,08 \\
\hline Indeterminada 12 & 1 & 8 & 0,08 & 0,00 & 0,00 & 0,08 \\
\hline Urticaceae 1 & 1 & 8 & 0,08 & 0,00 & 0,00 & 0,08 \\
\hline Eugenia macahensis & 1 & 8 & 0,08 & 0,00 & 0,00 & 0,08 \\
\hline Melastomataceae 2 & 1 & 8 & 0,08 & 0,00 & 0,00 & 0,08 \\
\hline Melastomataceae 11 & 1 & 8 & 0,08 & 0,00 & 0,00 & 0,08 \\
\hline Melastomataceae 10 & 1 & 8 & 0,08 & 0,00 & 0,00 & 0,08 \\
\hline
\end{tabular}

to be continued 
MOURA, C. de; MANTOVANI, W. Regeneração natural de floresta após oito anos de abandono da bananicultura.

continuação - Tabela 4

continuation - Table 4

\begin{tabular}{|c|c|c|c|c|c|c|}
\hline Espécie & NI & DeA & DeR & DoA & DoR & $\mathrm{VC}$ \\
\hline Myrceugenia campestris & 1 & 8 & 0,08 & 0,00 & 0,00 & 0,08 \\
\hline Indeterminada 16 & 1 & 8 & 0,08 & 0,00 & 0,00 & 0,08 \\
\hline Bignoniaceae 1 & 1 & 8 & 0,08 & 0,00 & 0,00 & 0,08 \\
\hline Acalypha diversifolia & 1 & 8 & 0,08 & 0,00 & 0,00 & 0,08 \\
\hline Pouteria beaurepairei & 1 & 8 & 0,08 & 0,00 & 0,00 & 0,08 \\
\hline Cinnamodendron dinisii & 1 & 8 & 0,08 & 0,00 & 0,00 & 0,08 \\
\hline Indeterminada 8 & 1 & 8 & 0,08 & 0,00 & 0,00 & 0,08 \\
\hline Sorocea hilarii & 1 & 8 & 0,08 & 0,00 & 0,00 & 0,08 \\
\hline Garcinia gardneriana & 1 & 8 & 0,08 & 0,00 & 0,00 & 0,08 \\
\hline Melastomataceae 7 & 1 & 8 & 0,08 & 0,00 & 0,00 & 0,08 \\
\hline Machaerium oblongifolium & 1 & 8 & 0,08 & 0,00 & 0,00 & 0,08 \\
\hline Cariniana estrellensis & 1 & 8 & 0,08 & 0,00 & 0,00 & 0,08 \\
\hline Melastomataceae 13 & 1 & 8 & 0,08 & 0,00 & 0,00 & 0,08 \\
\hline Copaifera trapezifolia & 1 & 8 & 0,08 & 0,00 & 0,00 & 0,08 \\
\hline Psychotria carthagenensis & 1 & 8 & 0,08 & 0,00 & 0,00 & 0,08 \\
\hline Miconia sp.2 & 1 & 8 & 0,08 & 0,00 & 0,00 & 0,08 \\
\hline Miconia pusilliflora & 1 & 8 & 0,08 & 0,00 & 0,00 & 0,08 \\
\hline Miconia cubatanensis & 1 & 8 & 0,08 & 0,00 & 0,00 & 0,08 \\
\hline Eugenia stigmatosa & 1 & 8 & 0,08 & 0,00 & 0,00 & 0,08 \\
\hline Citrus sp.* & 1 & 8 & 0,08 & 0,00 & 0,00 & 0,08 \\
\hline Indeterminada 7 & 1 & 8 & 0,08 & 0,00 & 0,00 & 0,08 \\
\hline Psychotria sp. & 1 & 8 & 0,08 & 0,00 & 0,00 & 0,08 \\
\hline Xylopia langsdorfiana & 1 & 8 & 0,08 & 0,00 & 0,00 & 0,08 \\
\hline Pera glabrata & 1 & 8 & 0,08 & 0,00 & 0,00 & 0,08 \\
\hline Indeterminada 9 & 1 & 8 & 0,08 & 0,00 & 0,00 & 0,08 \\
\hline Dalbergia frutescens & 1 & 8 & 0,08 & 0,00 & 0,00 & 0,08 \\
\hline Fabaceae 1 & 1 & 8 & 0,08 & 0,00 & 0,00 & 0,08 \\
\hline Melastomataceae 3 & 1 & 8 & 0,08 & 0,00 & 0,00 & 0,08 \\
\hline Indeterminada 10 & 1 & 8 & 0,08 & 0,00 & 0,00 & 0,08 \\
\hline Rudgea jasminoides & 1 & 8 & 0,08 & 0,00 & 0,00 & 0,08 \\
\hline Melastomataceae 12 & 1 & 8 & 0,08 & 0,00 & 0,00 & 0,08 \\
\hline Huberia aff. nettoana & 1 & 8 & 0,08 & 0,00 & 0,00 & 0,08 \\
\hline Indeterminada 14 & 1 & 8 & 0,08 & 0,00 & 0,00 & 0,08 \\
\hline Heteropterys aenea & 1 & 8 & 0,08 & 0,00 & 0,00 & 0,08 \\
\hline Cheiloclinium sp. & 1 & 8 & 0,08 & 0,00 & 0,00 & 0,08 \\
\hline Ocotea sp. & 1 & 8 & 0,08 & 0,00 & 0,00 & 0,08 \\
\hline Indeterminada 15 & 1 & 8 & 0,08 & 0,00 & 0,00 & 0,08 \\
\hline
\end{tabular}

to be continued 
MOURA, C. de; MANTOVANI, W. Regeneração natural de floresta após oito anos de abandono da bananicultura.

continuação - Tabela 4

continuation - Table 4

\begin{tabular}{lcccccc}
\hline Espécie & NI & DeA & DeR & DoA & DoR & VC \\
\hline Indeterminada 13 & 1 & 8 & 0,08 & 0,00 & 0,00 & 0,08 \\
Rubiaceae sp.1 & 1 & 8 & 0,08 & 0,00 & 0,00 & 0,08 \\
Myrtaceae 1 & 1 & 8 & 0,08 & 0,00 & 0,00 & 0,08 \\
Melastomataceae 6 & 1 & 8 & 0,08 & 0,00 & 0,00 & 0,08 \\
\hline
\end{tabular}

*Espécie exótica.

*Exotic species.

As espécies L. variabilis, T. pulchra, M. cinnamomifolia, Hyeronima alchorneoides, Myrsine coriacea, M. discolor e P. macropoda foram as mais representativas em termos de DeA e DeR, conforme consta na Tabela 2 e Figura 6.

T. pulchra foi a mais representativa com $10,04 \mathrm{~m}^{2} / \mathrm{ha}$ de DoA e 37,72\% de DoR, seguido por P. macropoda, Vernonanthura discolor, M. cinnamomifolia e L. variabilis (Tabela 2; Figura 6).
No período de realização do monitoramento não foi verificada qualquer perturbação externa que tenha interferido na regeneração natural que estava em curso na área de estudo.

Nos $1.250 \mathrm{~m}^{2}$ estudados, subdivididos em cinco parcelas de $10 \times 25 \mathrm{~m}$, foram encontradas 14 bananeiras (Musa sp.); desta maneira, levando em consideração que cada parcela de $250 \mathrm{~m}^{2}$, no espaçamento $2 \times 2 \mathrm{~m}$, comportaria o plantio de 62 pés de banana, onde cada planta ocuparia $4 \mathrm{~m}^{2}$, verificamos que a erradicação das bananeiras variou de $91,93 \%$ a $100 \%$ (Tabela 5).

Tabela 5. Indivíduos levantados por parcela e percentual de erradicação de bananeiras na área de estudo.

Table 5. Individuals surveyed per plot and percentage of banana eradication in the study area.

\begin{tabular}{cccc}
\hline Parcelas & $\mathrm{N}^{\mathrm{o}}$ total indiv. & $\mathrm{N}^{\mathrm{o}}$ bananeiras & \% erradicação \\
\hline 1D & 271 & 5 & $91,93 \%$ \\
2D & 348 & 0 & $100,00 \%$ \\
1C & 323 & 2 & $96,77 \%$ \\
3C & 266 & 3 & $95,16 \%$ \\
4C & 236 & 4 & $93,54 \%$ \\
\hline
\end{tabular}

\section{DISCUSSÃO}

Entre os 57 indivíduos mortos identificados, mais de 85\% são das espécies pioneiras Trema micrantha, Leandra variabilis, Cecropia sp., Tibouchina pulchra e Myrsine sp., que são espécies de crescimento rápido, ciclo de vida curto, que não toleram a sombra e produzem sementes pequenas, dispersas pela fauna (aves e morcegos) e pelo vento (Budowski, 1965).

No presente estudo, após oito anos de regeneração, foram registradas 149 espécies arbustivo-arbóreas $\geq 1 \mathrm{~m}$ de altura, em uma área amostral total de $1.250 \mathrm{~m}^{2}$. Torezan (1995) em Iporanga, Vale do Ribeira, SP, registrou a ocorrência de 185 morfoespécies, das quais 134 foram identificadas em nível específico, sendo 42 espécies na área de cinco anos e 57 espécies na de 15 anos. Já Oliveira (2002), estudando florestas secundárias originadas de plantios de subsistência na Ilha Grande, Angra dos Reis, RJ, superior a $2 \mathrm{~m}$ e DAP superior a 2,5 cm, registrou a ocorrência de 236 espécies, sendo 26 espécies na floresta de cinco anos e 70 espécies na de 10 anos, em áreas de $2.600 \mathrm{~m}^{2}$. 
MOURA, C. de; MANTOVANI, W. Regeneração natural de floresta após oito anos de abandono da bananicultura.

A diferença em relação a essas áreas se deve à distinção das características do entorno, ao histórico de uso e ao manejo que cada uma das áreas sofreu, pois a prática da agricultura de corte e queima pelas comunidades tradicionais utiliza o fogo recorrente como técnica de limpeza para erradicar plantas rasteiras e arbustivas das áreas de roça, transformando o material lenhoso em carvão, que serve para corrigir a acidez característica dos solos das florestas tropicais (Adams, 2000; Steiner et al., 2010).

No local do presente estudo houve o corte das plantas do sub-bosque, a queima, a implantação do bananal, a supressão da vegetação nativa de porte arbóreo, e, depois, a manutenção dos tratos culturais de capina, desbaste, colheita etc. Posteriormente, os tratos culturais foram interrompidos e não ocorreu nenhuma perturbação externa que pudesse interferir com o processo de regeneração natural. E como esta área é vizinha a remanescentes florestais bem estruturados, como os da Juréia, eles contribuíram para o fornecimento de sementes, conforme observado por Pivello et al. (2006) e Ferretti (2002).

No caso da Ilha Grande, essa diferença entre as florestas secundárias comparadas se deve também ao isolamento da área por sua condição de ilha, que impõe limitações maiores à colonização por espécies de plantas do que o continente, mostrando ser relevante para a interpretação da sucessão conhecer o histórico de uso dos locais, conforme afirmou Insernhagen et al. (2010b), e que as ações antrópicas são fatores importantes na sucessão.

Neste estudo, encontramos um pequeno conjunto de espécies pioneiras dominando o componente arbóreo-arbustivo, assim como Siminski et al. (2011) em estudo da sucessão secundária desenvolvido na floresta atlântica no estado de Santa Catarina, até cerca de 15 anos de sucessão, e Oliveira (2002), em uma área de cinco anos de regeneração na Ilha Grande, RJ.
O predomínio de espécies secundárias entre os grupos sucessionais mostra que o abandono dos bananais favorece o processo de regeneração natural, pois o sombreamento causado pelas folhas das bananeiras pode contribuir na seleção de espécies adaptadas à condição de pouca luminosidade (Solórzano et al., 2012), característica das espécies secundárias tardias e de sub-bosque (Budowski, 1965; Tabarelli et al., 1993).

Em uma paisagem florestal, como é o caso da área estudada na região da Juréia, onde existe elevada resiliência, ou seja, há capacidade de esse ambiente recuperar suas características anteriores após sofrer alguma perturbação, a interrupção de tratos culturais associada ao isolamento e abandono dos bananais foi suficiente para criar as condições que favoreceram a regeneração natural da vegetação nativa, conforme observado por Insernhagen et al. (2010a) e Jesus e Rolim (2005).

Essa capacidade de recuperação foi também confirmada por Torezan (1995), pelo relato de agricultores da região e observações de campo realizadas ao longo dos últimos 10 anos, em que foi apurado que no período de seis meses a um ano, aproximadamente, a vegetação regenerante consegue ultrapassar as bananeiras em altura e provoca um sombreamento que interfere drasticamente no desenvolvimento da cultura exótica, que vai sendo eliminada naturalmente ao longo do tempo, dando lugar a uma formação florestal secundária (Moura, 2016).

Neste estudo, encontramos 771 indivíduos e 29 espécies da família Melastomataceae, que foi responsável por $58,14 \%$ da DeR e 49,62\% da DoR constituindo, assim, a família de maior relevância na área de estudo.

Tabarelli e Mantovani (1999) observaram a tendência da predominância de arbustos e pequenas árvores de espécies pioneiras de Melastomataceae dos gêneros Miconia e Leandra em florestas em processo inicial de regeneração. 
MOURA, C. de; MANTOVANI, W. Regeneração natural de floresta após oito anos de abandono da bananicultura.

Estudando a sucessão florestal no Vale do Ribeira, Torezan (1995) considerou Melastomataceae como a família mais importante floristicamente, com maior riqueza específica, com 20 espécies, que se distribuem em toda cronossequência estudada, sendo quatro espécies na área de 5 anos, três na de 15 anos e 15 na de 50 anos, porém apenas Miconia cinnamomifolia e Tibouchina pulchra ocorreram em todas as áreas, e Leandra variabilis foi registrada somente nas áreas de 15 e 50 anos; e Siminski et al. (2011), em estudo de sucessão de florestas secundárias de Floresta Ombrófila Densa no estado de Santa Catarina, registraram M. cinnamomifolia e T. pulchra no estágio das arvoretas (de 8 a 15 anos).

Dessa maneira, os dados obtidos no presente estudo corroboram com os de Torezan (1995) e Siminski et al. (2011).

Melastomataceae possui distribuição predominantemente pantropical, incluindo cerca de 5.000 espécies das quais 1.000 ocorrem no Brasil, tornando-a uma das principais famílias da flora brasileira (Souza e Lorenzi, 2008). As características ecológicas de Melastomataceae, que possui grande número de espécies de início de sucessão florestal, faz com que ela seja importante no processo de sucessão ecológica de espécies florestais e abundantes em florestas degradadas ou em recuperação. Os gêneros Miconia e Leandra possuem diversas espécies pioneiras e secundárias iniciais que são espécies intolerantes ao sombreamento (Budowski, 1965), por este motivo esses grupos sucessionais predominam no local estudado com $36,91 \%$ das espécies levantadas.

A importância de Melastomataceae na composição da riqueza de espécies tem sido relatada em diversos levantamentos realizados na Serra do Mar (Mantovani et. al., 1990), na Serra da Cantareira (Arzolla et al., 2010), na Serra da Juréia (Mamede et al., 2001), na Serra de Paranapiacaba (Torezan, 1995; Aguiar, 2003); na Ilha do Cardoso (Barros et al., 1991), na Baixada Litorânea de Pariquera-Açú (Ivanauskas, 1997), na região do Vale do Ribeira
(Cofani-Nunes e Weissenberg, 2010) e no estado de São Paulo (Wanderley et al., 2011). Além de ter sido citada também nos estados do Rio de Janeiro (Lima e Guedes-Bruni, 1997), Paraná (Blum, 2006), Santa Catarina (Siminski et al., 2011), assim como para a Floresta Ombrófila Densa Atlântica como um todo (Stehmann et al., 2009), e está associada ao grande número de espécies de início de sucessão florestal mostrando sua importância no processo sucessional de florestas degradadas ou em recuperação.

Os gêneros Miconia, Cecropia e Myrsine estão entre os que apresentaram as maiores riquezas de espécies deste estudo, foram citados por Siminski et al. (2011) como bastante frequentes nas florestas secundárias da Mata Atlântica no Sul e Sudeste do Brasil.

Estudando a chuva de sementes entre remanescentes florestais em uma paisagem fragmentada, Pivello et al. (2006) verificaram que $80,7 \%$ das sementes eram de espécies arbóreas e $73,7 \%$ eram zoocóricas, com predomínio das espécies iniciais de sucessão e que a estrutura da vegetação é importante na determinação de padrões de hábito, tipo funcional e síndrome de dispersão das espécies contidas em chuvas de sementes.

$\mathrm{Na}$ área estudada, a zoocoria foi a síndrome de dispersão predominante para 54,36\% das espécies, que, segundo Mantovani (1990), é uma característica das famílias de angiospermas comuns da Floresta Ombrófila Densa Atlântica. O predomínio da zoocoria como síndrome de dispersão é característica das espécies pioneiras e secundárias (Budowski, 1965), que são abundantes na amostra e favorecidas pela cobertura florestal da Estação Ecológica Juréia-Itatins, da Estação Ecológica Juréia-Itatins, assim como pela sua alta diversidade de aves e morcegos (Develey, 2004; Gimenez e Ferrarezzi, 2004), que são os principais dispersores destes grupos de espécies (Budowski, 1965).

As características estruturais da área estudada estão relacionadas ao tempo de regeneração natural a que foram submetidas, 
MOURA, C. de; MANTOVANI, W. Regeneração natural de floresta após oito anos de abandono da bananicultura.

isto influenciou os valores de densidade absoluta, número de indivíduos amostrados, número de indivíduos mortos e número de indivíduos com caules múltiplos.

Como no local a regeneração é recente, predominaram as espécies pioneiras Tibouchina pulchra e Leandra variabilis, além da espécie secundária inicial Miconia cinnamomifolia, que apresentaram os maiores valores de dominância, densidade e VC evidenciando suas importâncias na sucessão florestal. Resultado semelhante foi obtido por Torezan (1995) em relação à densidade e dominância e VC de T. pulchra nas áreas de $5 \mathrm{e}$ 15 anos de regeneração, além de ter registrado a ocorrência de $M$. cinnamomifolia ao longo de toda a cronossequência estudada $(5,15$ e 50 anos de regeneração). M. cinnamomifolia foi indicada como uma das espécies mais importantes de uma floresta secundária de 50 anos, originária de um bananal abandonado no Maciço da Pedra Branca, RJ (Solórzano et al., 2012) e uma das cinco espécies que ocorrem em todas as áreas estudadas com 5, 25, 50 anos de regeneração e floresta madura na Ilha Grande, $\mathrm{RJ}$, onde apresentou os maiores valores de densidade e dominância relativas nas áreas de 25 e 50 anos de regeneração (Oliveira, 2002).

As espécies pioneiras Piptocarpha macropoda e Vernonanthura discolor (Asteraceae) também estão entre as que apresentaram os maiores valores de VC, porém somente alcançaram esta posição em função do grande porte dos indivíduos desta família na área estudada.

P. macropoda foi uma das espécies mais representativas em densidade, dominância e VC em áreas de clareira de origem antrópica na Serra da Cantareira (Arzolla, 2011), que relatou a ocorrência de outras três espécies do gênero Piptocarpha ( $P$. pyrifolia, $P$. quadrangularis e $P$. sellowii), excetuando-se o trabalho deste autor, esta espécie não tem sido relatada na maioria dos estudos realizados. Siminski et al. (2011) relatam a ocorrência de Piptocarpha angustifolia no estágio arbustivo e arbóreo de sucessão em florestas com idades entre 8-30 anos da Floresta Ombrófila Densa das regiões Sul e Sudeste do Brasil.

L. variabilis é uma espécie pioneira arbustiva que apresentou baixa dominância e por outro lado mostrou os maiores valores de densidade absoluta e relativa, mostrando ser uma espécie muito importante na sucessão florestal dominando o sub-bosque da floresta regenerante. Essa espécie apresentou o maior número de caules múltiplos do levantamento, provavelmente foi favorecida pela capina e roçada efetuadas no período em que o bananal ainda estava sendo manejado.

Torezan (1995) registrou Leandra variabilis nas áreas de 15 e 50 anos de regeneração entre as plantas de 0,1 a 2 metros de altura. Apesar de L. variabilis ser uma espécie restrita à Mata Atlântica, que ocorre da Bahia ao Rio Grande do Sul (Reginato e Goldenberg, 2012; Baumgratz e Souza, 2015), de maneira geral não tem sido registrada em estudos fitossociológicos, em função de seu porte ser arbustivo e de pequeno diâmetro, sendo mais comum seu registro em estudos florísticos e de regeneração natural tal como no presente trabalho e no realizado por Arzolla et al. (2010) na Serra da Cantareira.

Alguns estudos atribuem os caules múltiplos à rebrota de indivíduos que foram cortados no passado (Assumpção e Nascimento, 2000; Sá, 2002; Carvalho et al., 2007) e isto foi o que provavelmente aconteceu na área estudada, pois na formação do bananal não houve mecanização, o que causaria a destruição dos sistemas radiculares, impedindo a possibilidade de rebrota de caules.

Essa multiplicidade de caules de Leandra variabilis, associada à sua alta densidade, provavelmente influenciou o padrão de distribuição espacial agregado das espécies da área estudada, conforme Matteucci e Colma (1982). Uma das características relevantes à colonização pelas espécies pioneiras é o seu ciclo de vida curto (Budowski, 1965), cumprindo o papel de facilitadora, desaparecendo da área em alguns anos, 
MOURA, C. de; MANTOVANI, W. Regeneração natural de floresta após oito anos de abandono da bananicultura.

criando as condições adequadas de luminosidade para que a sucessão florestal ocorra, com a substituição de espécies, segundo o modelo proposto por Connell e Slatyer (1977).

Em relação ao índice de diversidade de Shannon-Wiener (H') e equabilidade (J'), os valores obtidos neste estudo estão próximos aos relatados para outras áreas de Floresta Ombrófila Densa com o mesmo tempo de regeneração, onde para florestas secundárias Floresta Ombrófila Densa Atlântica do Sul e Sudeste do Brasil, Siminski et al. (2011) obtiveram $\mathrm{H}^{\prime}=3,030$ nat. ind ${ }^{-1} \mathrm{e} \mathrm{J}=0,701$ para uma área com oito anos de regeneração, Oliveira (2002), na Ilha Grande, RJ, obteve $\mathrm{H}^{\prime}=2,510$ nat. ind ${ }^{-1}$ e $J^{\prime}=0,770$ para uma área com cinco anos e Torezan (1995), em Iporanga, SP, obteve diversidade que variou de $\mathrm{H}^{\prime}=2,000$ a 2,500 nat. ind $^{-1}$ para áreas de cinco e 15 anos de regeneração, respectivamente.

Considerando que a forma comum de erradicação das bananeiras utilizada pelos agricultores da região do Vale do Ribeira para renovação dos bananais é o corte manual das plantas (Arruda et al., 1993), e que este método também passou a ser utilizado para recuperação de áreas degradadas por força da legislação ambiental a um custo financeiro muito alto, os resultados obtidos mostram que nas condições estudadas a regeneração natural é uma técnica viável e de baixo custo, pois auxilia o processo de sucessão florestal favorecendo a formação de uma floresta secundária com elevada riqueza de espécies (147 espécies nativas) e alta densidade de indivíduos (10.608 ind./ha), que possibilitou erradicar de $91,93 \%$ a $100 \%$ das bananeiras anteriormente introduzidas no local estudado.

Solórzano et al. (2012) registraram no Parque Estadual da Pedra Branca, RJ, em $2.500 \mathrm{~m}^{2}$ de uma floresta com 50 anos de regeneração, dois indivíduos de bananeira (Musa sp.), espécie exótica introduzida na área por agricultores da região, mostrando a capacidade de bananeiras (Musa sp.) resistirem e permanecerem no ambiente por tanto tempo, inclusive pelo fato de se estabelecerem por brotação do rizoma das plantas. No entanto, na região de estudo, em levantamento para avaliar a contaminação da praga agrícola denominada broca-do-rizoma das bananeiras, efetuado no ano de 2014 em área com as mesmas condições e vizinha da área estudada, foi verificado que $90 \%$ dos indivíduos estavam infestados com a broca interferindo no desenvolvimento das plantas (Moura, 2016). A broca-do-rizoma é uma das pragas mais sérias e comuns da bananicultura, em que as larvas de besouros da espécie Cosmopolites sordidus se alimentam do rizoma, construindo galerias em toda sua extensão, enfraquecendo o desenvolvimento e provocando a morte das plantas (EMBRAPA, 2009).

\section{CONCLUSÕES}

A interrupção dos tratos culturais e o abandono da área degradada para implantação da bananicultura mostraram-se capazes de desencadear os processos de regeneração natural que permitiram a regeneração da vegetação nativa típica de Floresta Ombrófila Densa Submontana, com elevada riqueza de espécies e densidade de indivíduos, além de reduzir significativamente a população da espécie introduzida (Musa sp.) nas condições estudadas, de proximidade a remanescentes florestais bem conservados e isolamento de perturbações externas como gado, roçadas, fogo e outros distúrbios, podendo, assim, ser recomendada como uma forma promissora de recuperação ambiental em condições semelhantes.

\section{REFERÊNCIAS BIBLIOGRÁFICAS}

ADAMS, C. As roças e o manejo da Mata Atlântica pelos caiçaras: uma revisão. Interciencia, v. 25, n. 3, p. 143-150, 2000.

AGUIAR O.T. Comparação entre os métodos de quadrantes e parcelas na caracterização da composição florística e fitossociológica de um trecho de Floresta Ombrófila Densa no Parque Estadual "Carlos Botelho" - São Miguel Arcanjo, São Paulo. 2003. 119 f. Dissertação (Mestrado em Recursos Florestais) - Escola Superior de Agricultura "Luiz de Queiroz", Universidade de São Paulo, Piracicaba. 
MOURA, C. de; MANTOVANI, W. Regeneração natural de floresta após oito anos de abandono da bananicultura.

ANGIOSPERM PHYLOGENY GROUP - APG IV. An update of the Angiosperm Phylogeny Group classification for the orders and families of flowering plants: APG IV. Botanical Journal of the Linnean Society, v. 181, p. 1-20, 2016.

ARONSON, J.; DURIGAN, G.; BRANCALION, P.H.S. Conceitos e definições correlatos à ciência e à prática da restauração ecológica. IF Sér. Reg., n. 44, p. 1-38, 2011.

ARRUDA, S.T.; PEREZ, L.H.; BESSA JUNIOR, A.A. A Bananicultura no Vale do Ribeira caracterização dos sistemas de produção. Agricultura em São Paulo, v. 40, n. 1, p. 1-17, 1993.

ARZOLLA, F.A.R.D.P. Florística e fitossociologia de trecho da Serra da Cantareira, Núcleo Águas Claras, Parque Estadual da Cantareira, Mairiporã - SP. 2002. 184 f. Dissertação (Mestrado em Biologia Vegetal) - Programa de Pós-Graduação em Biologia Vegetal, Instituto de Biologia, Universidade Estadual de Campinas, Campinas.

\section{Florestas secundárias e a regeneração}

natural de clareiras antrópicas na Serra da Cantareira, SP. 2011. 141 f. Tese (Doutorado em Biologia Vegetal) - Programa de Pós-Graduação em Biologia Vegetal, Instituto de Biologia, Universidade Estadual de Campinas, Campinas.

. et al. Regeneração natural em clareiras de origem antrópica na Serra da Cantareira, SP. Revista do Instituto Florestal, v. 22, n. 1, p. $155-169,2010$.

. et al. Composição florística e a conservação de florestas secundárias na Serra da Cantareira, São Paulo, Brasil. Revista Instituto Florestal, v. 23, n. 1, p.149-171, 2011.

ASSUMPÇÃO, J.; NASCIMENTO, M.T. Estrutura e composição florística de quatro formações vegetais de restinga no complexo lagunar Grussaí/Iquipari, São João da Barra, RJ, Brasil. Acta bot. bras., v. 14, n. 3, p. 301-315, 2000.
BAIDER, C.; TABARELLI, M.; MANTOVANI, W. The soil seed bank during Atlantic Forest regeneration in Southeast Brazil. Revista Brasileira de Biologia, v. 61, n. 1, p. 35-44, 2001.

BARROS, F. et al. Caracterização geral da vegetação e listagem das espécies ocorrentes. In: MELO, M.M.R.F. et al. (Ed.). Flora fanerogâmica da Ilha do Cardoso. São Paulo: Hucitec, 1991. v. 1, p. 61-181.

BAUMGRATZ, J.F.A.; SOUZA, M.L.D.R. Leandra. In: LISTA de espécies da flora do Brasil. Jardim Botânico do Rio de Janeiro, 2015. Disponível em: <http://floradobrasil.jbrj.gov.br/jabot/ floradobrasil/FB9638>. Acesso em: 11 mar. 2015.

BLUM, C.T. A Floresta Ombrófila Densa na Serra da Prata, Parque Nacional Saint Hilaire/Lange, PR - caracterização florística, fitossociológica e ambiental de um gradiente altitudinal. 2006. 195 f. Dissertação (Mestrado em Ciências Florestais) - Pós-Graduação em Engenharia Florestal, Universidade Federal do Paraná, Curitiba.

BRASIL. Ministério do Meio Ambiente. Avaliação e ações prioritárias para a conservação da biodiversidade da Mata Atlântica e Campos Sulinos. Brasília, DF: MMA/SBF, 2000. 40 p.

BUDOWSKI, G. Distribution of tropical rain forest species in the light of successional processes. Turrialba, v. 15, n. 1, p. 40-2, 1965.

CADENASSO, M.L.; MEINERS, S.J.; PICKETT, S.T.A. The success of succession: a symposium commemorating the 50th anniversary of the Buell-Small Succession Study. Applied Vegetation Science, v. 12, p. 3-8, 2008.

CARPANEZZI, A.A. Fundamentos para a reabilitação de ecossistemas florestais. In: GALVÃO, P.M.; PORFÍRIO-DA-SILVA, V. (Ed.). Restauração florestal: fundamentos e estudos de caso. Colombo: Embrapa Florestas, 2005. p. 27-45. 
MOURA, C. de; MANTOVANI, W. Regeneração natural de floresta após oito anos de abandono da bananicultura.

CARVALHO, F.A.; NASCIMENTO, M.T.; BRAGA, J.M.A. Estrutura e composição florística do estrato arbóreo de um remanescente de Mata Atlântica Submontana no município de Rio Bonito, RJ, Brasil (Mata Rio Vermelho). Revista Árvore, V. 31, n. 4. p. 717-730, 2007.

CATHARINO, E.L.M. As florestas montanas da Reserva Florestal do Morro Grande, Cotia (São Paulo, Brasil). 2006. 246 f. Tese (Doutorado em Biologia Vegetal) - Programa de Pós-Graduação em Biologia Vegetal, Instituto de Biologia, Universidade Estadual de Campinas, Campinas.

CHAZDON, R.L. Regeneração de florestas tropicais. Boletim do Museu Paraense Emílio Goeldi, v. 7, n. 3, p. 195-218, 2012.

COFANI-NUNES, J.V.; WEISSENBERG, E.W. Flora do Vale do Ribeira: listagem das angiospermas. In: SILVA, R.B.; MING, L.C. (Ed.). Polo de biotecnologia da Mata Atlântica: relatos de pesquisas e outras experiências vividas no Vale do Ribeira. Jaboticabal: Multipress, 2010. p. 61-94.

CONNELL, J.H.; SLATYER, R.O. Mechanisms of succession in natural communities and their role in community stability and organization. The American Naturalist, v. 111, n. 982, p. 1119-1144, 1977.

CONSELHO NACIONAL DO MEIO AMBIENTE - CONAMA. Resolução CONAMA $\mathrm{n}^{\circ} 10$ de 01 de outubro de 1993. Estabelece os parâmetros básicos para análise dos estágios de sucessão de Mata Atlântica. Diário Oficial da União, n. 209, 3 nov. 1993. Seção 1, p. 16497-16498. Disponível em: <http://www.mma.gov.br/port/ conama/legiabre.cfm?codlegi=135>. Acesso em: 20 dez. 2016.

DEVELEY, P.F. As aves da Estação Ecológica Juréia-Itatins. In: MARQUES, O.A.V.; DULEBA, W. (Ed.). Estação Ecológica de Juréia-Itatins: ambiente físico, flora e fauna. Ribeirão Preto: Holos, 2004. p. 278-295.
DURIGAN, G. Estrutura e diversidade de comunidades florestais. In: MARTINS, S.V. (Ed.). Ecologia de florestas tropicais do Brasil. Viçosa-MG: UFV, 2009. p. 185-215.

. et al. Regeneração natural da vegetação de cerrado sob florestas plantadas com espécies nativas e exóticas. In: VILAS BÔAS, O.; DURIGAN, G. (Org.). Pesquisas em conservação e recuperação ambiental no oeste paulista. São Paulo: Páginas \& Letras, 2004. p. 349-362.

EMPRESA BRASILEIRA DE PESQUISA AGROPECUÁRIA - EMBRAPA. Recuperação de áreas degradadas. In: WADT, P.G.S. (Ed.). Práticas de conservação do solo e recuperação de áreas degradadas. Rio Branco: EMBRAPA Acre, 2003. p. 20-27.

Sistema de produção da bananeira irrigada. Embrapa Semiárido. Sistemas de Produção, 4, jul./2009. Disponível em: $<$ http://sistemasdeproducao.cnptia.embrapa.br/ FontesHTML/Banana/BananeiraIrrigada/pragas. htm>. Acesso em: 14 mar. 2014.

FERRETTI, A.R. Modelos de plantio para a restauração. In: GALVÃO, A.P.M.; MEDEIROS, A.C.S. (Ed.). A restauração da Mata Atlântica em áreas de sua primitiva ocorrência natural. Colombo: Embrapa Florestas, 2002. p. 35-43.

FIDALGO, O.; BONONI, V.L.R. (Coord.). Técnicas de coleta, preservação e herborização de material botânico. São Paulo: Instituto de Botânica, 1984. 62 p. (Manual n. 4).

FORZZA, R.C. (Coord.). Angiospermas. In: FLORA do Brasil 2020 em construção. Rio de Janeiro: Jardim Botânico do Rio de Janeiro. Disponível em: $<$ http://reflora.jbrj.gov.br/reflora/ floradobrasil/FB128482>. Acesso em: 22 jun. 2016.

GANDOLFI, S.; LEITÃO FILHO, H.F.; BEZERRA, C.L. Levantamento florístico e caráter sucessional das espécies arbustivo-arbóreas de uma floresta mesófila semidecídua no Município de Guarulhos, SP. Revista Brasileira de Biologia, v. 55, p. 753-767, 1995. 
MOURA, C. de; MANTOVANI, W. Regeneração natural de floresta após oito anos de abandono da bananicultura.

GIMENEZ, E.A.; FERRAREZZI, H. Diversidade de morcegos no Sudeste da Mata Atlântica. In: MARQUES, O.A.V.; DULEBA, W. (Ed.). Estação Ecológica de Juréia-Itatins: ambiente físico, flora e fauna. Ribeirão Preto: Holos, 2004. p. 314-330.

GUARIGUATA, M.R.; OSTERTAG, R. Neotropical secondary forest succession: changes in structural and functional characteristics. Forest Ecology and Management, v. 148, n. 1, p. 185-206, 2001.

INSERNHAGEN, I. et al. Diagnóstico ambiental das áreas a serem restauradas visando a definição de metodologias de restauração florestal. In: RODRIGUES, R.R.; BRANCALION, P.H.S.; INSERNHAGEN, I. (Org.). Pacto pela restauração da Mata Atlântica: referencial dos conceitos e ações de restauração florestal. 3. ed. São Paulo: LERF, 2010a. p. 91-130.

et al. Principais iniciativas de restauração florestal na Mata Atlântica, apresentadas sob a ótica da evolução dos conceitos e dos métodos aplicativos: Fase 4. In: RODRIGUES, R.R.; BRANCALION, P.H.S.; INSERNHAGEN, I. (Org.). Pacto pela restauração da Mata Atlântica: referencial dos conceitos e ações de restauração florestal. 3. ed. São Paulo: LERF, 2010b. p. $35-41$.

INSTITUTO BRASILEIRO DE GEOGRÁFIA E ESTATÍSTICA - IBGE. Manual técnico da vegetação brasileira. 2. ed. rev. e ampl. Rio de Janeiro: Coordenação de Recursos Naturais e Estudos Ambientais, 2012. 271 p. (Manuais Técnicos em Geociências, n. 1).

IVANAUSKAS, N.M. Caracterização florística e fisionômica da Floresta Atlântica sobre a Formação Pariquera-Açu, na Zona de Morraria Costeira do Estado de São Paulo. 1997. 216 f. Dissertação (Mestrado em Biologia Vegetal) Instituto de Biologia, Universidade Estadual de Campinas, Campinas.
JESUS, R.M.; ROLIM, S.G. Experiências relevantes na restauração da Mata Atlântica. In: GALVÃO, P.M.; PORFÍRIO-DA-SILVA, V. (Ed.). Restauração florestal: fundamentos e estudos de caso. Colombo: Embrapa Florestas, 2005. p. 59-86.

KRONKA, F.J.N. et al. Inventário florestal da vegetação natural do Estado de São Paulo regiões administrativas de São José dos Campos (Litoral), Baixada Santista e Registro. São Paulo: Imprensa Oficial, 2007. 140 p.

LEWINSOHN, T.M.; PRADO, P.I. Biodiversidade brasileira: síntese atual do conhecimento. São Paulo: Contexto, 2002. 176 p.

LIMA, H.C.; GUEDES-BRUNI, R.R. Diversidade de plantas vasculares na Reserva Ecológica de Macaé de Cima. In: LIMA, H.C.; GUEDES-BRUNI, R.R. (Ed.). Serra de Macaé de Cima: diversidade florística e conservação em Mata Atlântica. Rio de Janeiro: Instituto de Pesquisas Jardim Botânico do Rio de Janeiro, 1997. p. 29-39.

MAMEDE, M.C.H.; CORDEIRO, I.; ROSSI, L. Flora vascular da Serra da Juréia - Iguape, SP. Boletim do Instituto de Botânica, n. 15, p. 63-124, 2001.

MANTOVANI, W. A dinâmica da floresta na encosta atlântica. In: SIMPÓSIO DE ECOSSISTEMAS DA COSTA SUL E SUDESTE BRASILEIRA: ESTRUTURA, FUNÇÃO E MANEJO, 2., 1990, Águas de Lindóia. Anais... Águas de Lindóia: ACIESP, 1990. v. 1, p. 304-313.

et al. A vegetação na Serra do Mar em Salesópolis, SP. In: SIMPÓSIO DE ECOSSISTEMAS DA COSTA SUL E SUDESTE BRASILEIRA: ESTRUTURA, FUNÇÃO E MANEJO, 2., 1990, Águas de Lindóia. Anais... Águas de Lindóia: ACIESP, 1990. v. 1, p. 348-384.

MARTINS, F.R. Estrutura de uma floresta mesófila. Campinas: UNICAMP, 1991. 246 p. (Série Teses).

MATTEUCCI, S.D.; COLMA, A. Metodologia para el estudio de la vegetación. Washington, D.C.: Secretaría General de la Organización de los Estados Americanos, Programa Regional de Desarrollo Científico y Tecnológico, 1982. 86 p. (Serie de Biología, Monografia, n. 22). 
MOURA, C. de; MANTOVANI, W. Regeneração natural de floresta após oito anos de abandono da bananicultura.

MORISITA, M. Id-index, a measure of dispersion of individuals. Researches on Population Ecology, v. 4, p. 1-7, 1962.

MORRONE, J.J. Biogeografía de América Latina y el Caribe. Zaragoza: Gorfi, 2001. 148 p. (M\&T-Manuales \& Tesis SEA, v. 3).

MOURA, C. Caracterização da dinâmica da regeneração natural de duas fisionomias de Floresta Ombrófila Densa degradadas na região da Juréia, Litoral Sul/Vale do Ribeira, SP. 2016. 110 f. Dissertação (Mestrado em Ciências) Programa de Pós-Graduação em Ciência Ambiental, Instituto de Energia e Ambiente, Universidade de São Paulo, São Paulo.

MUELLER-DOMBOIS, D.; ELLEMBERG, $\mathrm{H}$. Aims and methods of vegetation ecology. New York: John Wiley, 1974. 574 p.

MYERS, N. et al. Biodiversity hotspots for conservation priorities. Nature, v. 403, n. 6772, p. 853-858, 2000. Disponível em: <http:/www.nature.com/nature/ journal/v403/n6772/pdf/403853a0.pdf > . Acesso em: 27 nov. 2009.

NALON, M.A.; MATTOS, I.F.A.; FRANCO, G.A.D.C. Meio físico e aspectos da fragmentação da vegetação. In: RODRIGUES, R.R.; BONONI, V.L.R. (Org.). Diretrizes para a restauração da biodiversidade no Estado de São Paulo. São Paulo: Instituto de Botânica: Imprensa Oficial, 2008. p. 14-21.

OLIVEIRA, R.R. Ação antrópica e resultantes sobre a estrutura e composição da Mata Atlântica na Ilha Grande, RJ. Rodriguésia, v. 53, n. 82, p. 33-58, 2002.

PIELOU, E.C. Ecological diversity. New York: John Willey. 1975. 165 p.

PIJL, L. Principles of dispersal in higher plants. Berlin: Springer-Verlag, 1969. 153 p.

PIVELLO, V.R. et al. Chuva de sementes em fragmentos de Floresta Atlântica (São Paulo, SP, Brasil), sob diferentes situações de conectividade, estrutura florestal e proximidade da borda. Acta bot. bras., v. 20, n. 4, p. 845-859, 2006.
PRADO, J.; SYLVESTRE, L.S. As samambaias e licófitas do Brasil. In: FORZZA, R.C. et al. (Org.). Catálogo de plantas e fungos do Brasil. Rio de Janeiro: Andrea Jakobsson Estúdio: Instituto de Pesquisas Jardim Botânico do Rio de Janeiro, 2010. v. 1, p. $70-75$.

- Samambaias e licófitas. In: FLORA do Brasil 2020 em construção. Jardim Botânico do Rio de Janeiro, 2016. Disponível em: $<$ http://reflora.jbrj.gov.br/reflora/floradobrasil/ FB128483>. Acesso em: 22 jun. 2016.

REGINATO, M.; GOLDENBERG, R. Taxonomic notes on Leandra (Melastomataceae, Miconieae). Hoehnea, v. 39, n. 2, p. 201-206, 2012.

SÁ, C.F.C. Regeneração de um trecho de floresta de restinga na Reserva Ecológica Estadual de Jacarepiá, Saquarema, Estado do Rio de Janeiro: II - Estrato arbustivo. Rodriguésia, v. 53, n. 82, p. 5-23, 2002.

SÃO PAULO (Estado). Levantamento censitário de unidades de produção agrícola do Estado de São Paulo - LUPA 2007/2008. São Paulo: SAA/CATI/IEA, 2008. Disponível em: $<$ http://www.cati.sp.gov.br/projetolupa $>$ Acesso em: 29 jan. 2016.

Lei $\mathrm{n}^{\mathrm{o}} 14.982 / 2013$, de 8 de abril de 2013. Altera os limites da Estação Ecológica da Jureia-Itatins na forma que especifica, e dá outras providências. (Cria o Mosaico de Unidades de Conservação Juréia-Itatins). Diário Oficial do Estado de São Paulo, v. 123 , n. 65 , p. 1-5, 9 abr. 2013. Disponível em: $<$ http://dobuscadireta.imprensaoficial.com.br/ default.aspx? DataPublicacao $=20130409 \&$ Caderno=DOE-I\&NumeroPagina $=1>$. Acesso em: 12 abr. 2013. 
MOURA, C. de; MANTOVANI, W. Regeneração natural de floresta após oito anos de abandono da bananicultura.

SÃO PAULO. (Estado). Levantamento de área e produção dos principais produtos da agropecuária do Estado de São Paulo. São Paulo: SAA/IEA/CATI, 2015. Disponível em: <http://ciagri.iea.sp.gov.br/ nia1/subjetiva.aspx?cod_sis=1\&idioma $=1>$. Acesso em: 2 dez. 2016.

SHEPHERD, G.J. Fitopac versão 2.1 - manual do usuário. Campinas: Departamento de Botânica, Universidade Estadual de Campinas, 2010. Disponível em: <http://pedroeisenlohr.webnode. com.br/fitopac/>. Acesso em: 10 nov. 2014.

SIMINSKI, A. et al. Secondary forest succession in the Mata Atlântica, Brazil: floristic and phytosociological trends. International Scholarly Research Network Ecology, v. 2011, p. 1-19, 2011.

SMITH-GILL, S.J. Cytophysiological basis of disruptive pigmentary patterns in the leopard frog, Rana pipiens. II. Wild type and mutant cell specific patterns. Journal of Morphology, v. 146, n. 1, p. 35-54, 1975.

SOBRAL, M.; JARENKOW, J.A. (Org.). Flora árborea e arborescente do Rio Grande do Sul, Brasil. São Carlos: RiMa: Novo Ambiente, 2006. $350 \mathrm{p}$.

SOLÓRZANO, A.; GUEDES-BRUNI, R.R.; OLIVEIRA, R.R. Composição florística e estrutura de um trecho de Floresta Ombrófila Densa Atlântica com uso pretérito de produção de banana, no Parque Estadual da Pedra Branca, Rio de Janeiro, RJ. Revista Árvore, v. 36, n. 3, p. 451-462, 2012.

SOUZA, C.R.G.; SOUZA, A.P. Geologia e geomorfologia da área da Estação Ecológica Juréia-Itatins. In: MARQUES, O.A.V.; DULEBA, W. (Ed.). Estação Ecológica Juréia-Itatins: ambiente físico, flora e fauna. Ribeirão Preto: Holos, 2004. p. 16-33.

SOUZA, V.C.; LORENZI, H. Botânica sistemática: guia ilustrado para a identificação das famílias de Fanerógamas nativas e exóticas no Brasil, baseado em APG II. 2. ed. Nova Odessa: Plantarum, 2008. 704 p.
STEHMANN, J.R. et al. Gimnospermas e Angiospermas. In: STEHMANN, J.R. et al. (Ed.). Plantas da Floresta Atlântica. Rio de Janeiro: Jardim Botânico do Rio de Janeiro, 2009. p. 27-37.

STEINER, C. et al. Corte e carbonização como uma alternativa ao corte e queima: estudos na Amazônia. In: TEIXEIRA, W.G. et al. (Ed.). As terras pretas de índio da Amazônia: sua caracterização e uso deste conhecimento na criação de novas áreas. Manaus: EDUA: Embrapa Amazônia Ocidental, 2010. p. 298-306.

TABARELLI, M.; VILLANI, J.P.; MANTOVANI, W. Aspectos da sucessão secundária em trecho da floresta atlântica no Parque Estadual da Serra do Mar, SP. Revista do Instituto Florestal, v. 5, n. 1, p. 99-112, 1993.

; MANTOVANI, W. A regeneração de uma floresta tropical montana após corte e queima (São Paulo-Brasil). Revista Brasileira de Biologia, v. 59, n. 2, 239-250, 1999.

TARIFA, J.F. Unidades climáticas dos Maciços Litorâneos da Juréia-Itatins. In: MARQUES, O.A.V.; DULEBA, W. (Ed.). Estação Ecológica de Juréia-Itatins: ambiente físico, flora e fauna. Ribeirão Preto: Holos, 2004. p. 42-50.

TEIXEIRA, L.A.J. et al. Banana - Musa spp. In: AGUIAR, A.T.E. et al. (Ed.). Instruções agrícolas para as principais culturas econômicas. 7. ed. rev. e atual. Campinas: Instituto Agronômico, 2014. p. 46-51. (Boletim IAC, n. 200).

TOREZAN, J.M.D. Estudo da sucessão secundária, na Floresta Ombrófila Densa Submontana, em áreas anteriormente cultivadas pelo sistema de "Coivara", em Iporanga-SP. 1995. 89 f. Dissertação (Mestrado em Botânica) Departamento de Botânica, Universidade Federal do Paraná, Curitiba. 
MOURA, C. de; MANTOVANI, W. Regeneração natural de floresta após oito anos de abandono da bananicultura.

XAVIER, A.F.; BOLZANI, B.M.; JORDÃO, S. Unidades de Conservação da Natureza no Estado de São Paulo. In: RODRIGUES, R.R.; BONONI, V.L.R. (Org.). Diretrizes para a restauração da biodiversidade no Estado de São Paulo. São Paulo: Instituto de Botânica: Imprensa Oficial, 2008. p. 22-42.

WANDERLEY, M.G.L. et al. Checklist das Spermatophyta do Estado de São Paulo, Brasil. Biota Neotropica, v. 11, n. 1a, p. 193-390, 2011. Disponível em: <http://www.biotaneotropica.org.br/ v11n1a/en/abstract?inventory+bn0131101a2011>. Acesso em: 3 mar. 2015. 